University of Wollongong

Research Online

Faculty of Science, Medicine and Health -

Papers: part A

Faculty of Science, Medicine and Health

$1-1-2013$

\title{
Regolith formation rate from U-series nuclides: Implications from the study of a spheroidal weathering profile in the Rio Icacos watershed (Puerto Rico)
}

F Chabaux

Universite de Strasbourg et CNRS

E Blaes

Universite de Strasbourg et CNRS

P Stille

Universite de Strasbourg et CNRS

R Di Chiara Roupert

Universite de Strasbourg et CNRS

E Pelt

Universite de Strasbourg et CNRS

See next page for additional authors

Follow this and additional works at: https://ro.uow.edu.au/smhpapers

\section{Recommended Citation}

Chabaux, F; Blaes, E; Stille, P; Di Chiara Roupert, R; Pelt, E; Dosseto, A; Ma, L; Buss, H L.; and Brantley, S, "Regolith formation rate from U-series nuclides: Implications from the study of a spheroidal weathering profile in the Rio Icacos watershed (Puerto Rico)" (2013). Faculty of Science, Medicine and Health Papers: part A. 60.

https://ro.uow.edu.au/smhpapers/60

Research Online is the open access institutional repository for the University of Wollongong. For further information contact the UOW Library: research-pubs@uow.edu.au 


\title{
Regolith formation rate from U-series nuclides: Implications from the study of a spheroidal weathering profile in the Rio Icacos watershed (Puerto Rico)
}

\author{
Abstract \\ A 2 m-thick spheroidal weathering profile, developed on a quartz diorite in the Rio Icacos watershed \\ (Luquillo Mountains, eastern Puerto Rico), was analyzed for major and trace element concentrations, $\mathrm{Sr}$ \\ and $\mathrm{Nd}$ isotopic ratios and U-series nuclides (238U-234U-230Th-226Ra). In this profile a $40 \mathrm{~cm}$ thick \\ soil horizon is overlying a $150 \mathrm{~cm}$ thick saprolite which is separated from the basal corestone by a $\sim 40$ \\ $\mathrm{cm}$ thick rindlet zone. The $\mathrm{Sr}$ and $\mathrm{Nd}$ isotopic variations along the whole profile imply that, in addition to \\ geochemical fractionations associated to water-rock interactions, the geochemical budget of the profile \\ is influenced by a significant accretion of atmospheric dusts. The mineralogical and geochemical \\ variations along the profile also confirm that the weathering front does not progress continuously from \\ the top to the base of the profile. The upper part of the profile is probably associated with a different \\ weathering system (lateral weathering of upper corestones) than the lower part, which consists of the \\ basal corestone, the associated rindlet system and the saprolite in contact with these rindlets. \\ Consequently, the determination of weathering rates from 238U-234U-230Th-226Ra disequilibrium in a \\ series of samples collected along a vertical depth profile can only be attempted for samples collected in \\ the lower part of the profile, i.e. the rindlet zone and the lower saprolite. Similar propagation rates were \\ derived for the rindlet system and the saprolite by using classical models involving loss and gain \\ processes for all nuclides to interpret the variation of U-series nuclides in the rindlet-saprolite subsystem. \\ The consistency of these weathering rates with average weathering and erosion rates derived via other \\ methods for the whole watershed provides a new and independent argument that, in the Rio Icacos \\ watershed, the weathering system has reached a geomorphologic steady-state. Our study also indicates \\ that even in environments with differential weathering, such as observed for the Puerto Rico site, the \\ radioactive disequilibrium between the nuclides of a single radioactive series (here \\ $238 \mathrm{U}-234 \mathrm{U}-230 \mathrm{Th}-226 \mathrm{Ra}$ ) can still be interpreted in terms of a simplified scenario of congruent \\ weathering. Incidentally, the U-Th-Ra disequilibrium in the corestone samples confirms that the \\ outermost part of the corestone is already weathered.
}

\section{Keywords}

study, rate, formation, u, regolith, series, rico, puerto, implications, watershed, nuclides, icacos, rio, profile, weathering, spheroidal

\section{Publication Details}

Chabaux, F., Blaes, E., Stille, P., Di Chiara Roupert, R., Pelt, E., Dosseto, A., Ma, L., Buss, H. L. \& Brantley, S. (2013). Regolith formation rate from U-series nuclides: Implications from the study of a spheroidal weathering profile in the Rio Icacos watershed (Puerto Rico). Geochimica et Cosmochimica Acta, 100 (N/ A), 73-95.

\section{Authors}

F Chabaux, E Blaes, P Stille, R Di Chiara Roupert, E Pelt, A Dosseto, L Ma, H L. Buss, and S Brantley 


\title{
Regolith formation rate from U-series nuclides: Implications from the study of a spheroidal weathering profile in the Rio Icacos watershed (Puerto Rico)
}

\author{
F. Chabaux ${ }^{\mathrm{a}, *}$, E. Blaes ${ }^{\mathrm{a}}$, P. Stille ${ }^{\mathrm{a}}$, R. di Chiara Roupert ${ }^{\mathrm{a}}$, E. Pelt ${ }^{\mathrm{a}}$, A. Dosseto ${ }^{\mathrm{b}}$, \\ L. Ma ${ }^{\mathrm{c}, 1}$, H.L. Buss ${ }^{\mathrm{d}, 2}$, S.L. Brantley ${ }^{\mathrm{c}}$

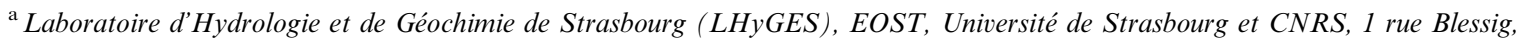 \\ 67084 Strasbourg Cedex, France \\ ${ }^{\mathrm{b}}$ GeoQuEST Research Centre, School of Earth and Environmental Sciences, University of Wollongong, Wollongong, NSW 2522, Australia \\ ${ }^{\mathrm{c}}$ Earth and Environmental Systems Institute and The Energy Institute, The Pennsylvania State University, University Park, PA 16802, USA \\ ${ }^{\mathrm{d}}$ U.S. Geological Survey, Menlo Park, CA 94025, USA
}

Received 7 October 2011; accepted in revised form 21 September 2012; available online 3 October 2012

\begin{abstract}
A 2 m-thick spheroidal weathering profile, developed on a quartz diorite in the Rio Icacos watershed (Luquillo Mountains, eastern Puerto Rico), was analyzed for major and trace element concentrations, $\mathrm{Sr}$ and $\mathrm{Nd}$ isotopic ratios and U-series nuclides $\left({ }^{238} \mathrm{U}-{ }^{234} \mathrm{U}-{ }^{230} \mathrm{Th}-{ }^{226} \mathrm{Ra}\right)$. In this profile a $40 \mathrm{~cm}$ thick soil horizon is overlying a $150 \mathrm{~cm}$ thick saprolite which is separated from the basal corestone by a $\sim 40 \mathrm{~cm}$ thick rindlet zone. The $\mathrm{Sr}$ and $\mathrm{Nd}$ isotopic variations along the whole profile imply that, in addition to geochemical fractionations associated to water-rock interactions, the geochemical budget of the profile is influenced by a significant accretion of atmospheric dusts. The mineralogical and geochemical variations along the profile also confirm that the weathering front does not progress continuously from the top to the base of the profile. The upper part of the profile is probably associated with a different weathering system (lateral weathering of upper corestones) than the lower part, which consists of the basal corestone, the associated rindlet system and the saprolite in contact with these rindlets. Consequently, the determination of weathering rates from ${ }^{238} \mathrm{U}-{ }^{234} \mathrm{U}-{ }^{230} \mathrm{Th}-{ }^{226} \mathrm{Ra}$ disequilibrium in a series of samples collected along a vertical depth profile can only be attempted for samples collected in the lower part of the profile, i.e. the rindlet zone and the lower saprolite. Similar propagation rates were derived for the rindlet system and the saprolite by using classical models involving loss and gain processes for all nuclides to interpret the variation of U-series nuclides in the rindletsaprolite subsystem. The consistency of these weathering rates with average weathering and erosion rates derived via other methods for the whole watershed provides a new and independent argument that, in the Rio Icacos watershed, the weathering system has reached a geomorphologic steady-state. Our study also indicates that even in environments with differential weathering, such as observed for the Puerto Rico site, the radioactive disequilibrium between the nuclides of a single radioactive series (here ${ }^{238} \mathrm{U}^{234} \mathrm{U}-{ }^{230} \mathrm{Th}-{ }^{226} \mathrm{Ra}$ ) can still be interpreted in terms of a simplified scenario of congruent weathering. Incidentally, the U-Th-Ra disequilibrium in the corestone samples confirms that the outermost part of the corestone is already weathered.
\end{abstract}

(C) 2012 Elsevier Ltd. All rights reserved.

\footnotetext{
* Corresponding author.

E-mail address: fchabaux@unistra.fr (F. Chabaux).

${ }^{1}$ Present address: Department of Geological Sciences, University of Texas at El Paso, El Paso, TX 79968, USA.

${ }^{2}$ Present address: School of Earth Sciences, University of Bristol, Wills Memorial Building, Queen's Rd, Bristol BS8 1RJ, UK.
} 


\section{INTRODUCTION}

Quantification of regolith formation rates, which is the rate at which a bedrock is converted to erodible regolith through physical, chemical, biological and hydrological processes, is important for the understanding of the development of weathering profiles and for the prediction of their evolution in response to environmental modification due to tectonic, climatic or anthropogenic forcings (e.g., Brantley et al., 2007; Brantley, 2008; Banwart et al., 2011). Analysis of U-series nuclides in soils and weathering profiles is one of only few radiochronological methods that allow direct determination of such a time parameter (e.g., Rosholt, 1982; Chabaux et al., 2003a, 2008, 2011; Dosseto et al., 2008, 2012).

The potential of U-series nuclides for identifying regolith production rates, by analyzing samples from weathering profiles has been recognized since the mid-1960s (Rosholt et al., 1966; Hansen and Stout, 1968). Studies in this field of research, however, progressed only recently (Boulad et al., 1977; Mathieu et al., 1995; Dequincey et al., 1999, 2002; Chabaux et al., 2003b; Dosseto et al., 2008, 2012; Pelt et al., 2008; Blaes et al., 2009; Ma et al., 2010,2012 ). This was certainly stimulated by the analytical improvements made during the last decade for the measurement of ${ }^{238} \mathrm{U}$-series nuclides (see Bourdon et al., 2003; Chabaux et al., 2008). The recent focus on U-series isotopes is probably also a consequence of an increasing awareness that the determination of weathering time-scales is a key for understanding and modeling the evolution of the continental surfaces and their response to the environmental changes expected to occur in the near future (e.g., Brantley, 2008).

Several studies, mainly based on the analysis of ${ }^{238} \mathrm{U}-{ }^{234} \mathrm{U}-{ }^{230} \mathrm{Th}$ nuclides and the use of the three activity ratios $\left({ }^{234} \mathrm{U} /{ }^{238} \mathrm{U}\right)-\left({ }^{230} \mathrm{Th} /{ }^{234} \mathrm{U}\right)-\left({ }^{230} \mathrm{Th} /{ }^{232} \mathrm{Th}\right.$ ) (activity ratios will be noted hereafter with parenthesis) recently provided important theoretical elements for the determination of regolith production rates in weathering profiles (e.g., Dequincey et al., 2002; Chabaux et al., 2003b, 2008, 2011; Dosseto et al., 2008; Ma et al., 2010). In all these studies the determination of a regolith production rate relies on the analysis of a series of samples collected along the main weathering direction of the system. Using U-series nuclides and a realistic model describing the behavior of these nuclides during weathering allow for constraining the model parameters, namely mobility coefficients of U-series nuclides and the age of each sample relative to a reference sample. The variation of these ages in function of the distance from the reference sample permits to derive the regolith production rate. If the volume variation associated to the transformation of bedrock into saprolite is known, then the propagation rate of the bedrockregolith interface into the bedrock, i.e., the propagation rate of the weathering front can be calculated. Such studies showed that the modeling approach is well suited to relatively simple alteration systems such as the weathering of basaltic clasts (Pelt et al., 2008; Ma et al., 2012) or of weathering profiles developed over shale (Ma et al., 2010) or andesite (Dosseto et al., 2012). On the other hand, for weathering profiles with more complex history such as lateritic profiles, the data interpretation in terms of the propagation rate of the weathering front is more complex (e.g., Dequincey et al., 2002; Chabaux et al., 2003b).

The aim of the present study is to go more deeply into the application of the analysis of U-series nuclides and to determine the regolith production rate in soils and weathering profiles. Here we propose to study in addition to the ${ }^{238} \mathrm{U}-{ }^{234} \mathrm{U}-{ }^{230} \mathrm{Th}$ nuclides the ${ }^{226} \mathrm{Ra}$, the direct radioactive decay product of the traditionally used ${ }^{230} \mathrm{Th}$.

The studied site is a 2 m-thick spheroidal weathering profile which developed on a quartz diorite in the Rio Icacos watershed located in a tropical rain forest of the Luquillo Mountains, eastern Puerto Rico; this site has been extensively studied before in order to elucidate weathering and erosion processes (McDowell and Asbury, 1994; Brown et al., 1995; White et al.,1998; Riebe et al., 2003; Turner et al., 2003; Buss et al., 2008; Pett-Ridge et al., 2009a; Ferrier et al., 2010). It is marked by one of the fastest chemical weathering rates of granitoid rocks ever documented for the Earth's surface (e.g., White et al., 1998; Millot et al., 2002; Viville et al., 2012). The comparison of the time information obtained from the U-series nuclide study with those derived from other approaches on this site will help to evaluate the current state of the stability of the Rio Icacos erosion system. In addition to the $\mathrm{U}$-series nuclides, major and trace element concentrations as well as $\mathrm{Sr}$ and $\mathrm{Nd}$ isotopic ratios have been analyzed; this indeed allows to identify the principal geochemical processes co-occurring during regolith formation and causing U-Th-Ra mobilities, which is a prerequisite for the correct interpretation of the time information derived from U-series nuclides (e.g., Dequincey et al., 2002; Pelt et al., 2008).

\section{STUDY AREA AND SAMPLE COLLECTION}

The Rio Icacos watershed is located in a lower montane wet forest (Cyrilla racemiflora) in the Luquillo Mountains of eastern Puerto Rico (Fig. 1). The 326 ha basin ranges in elevation from 600 to $800 \mathrm{~m}$. The mean annual temperature is $22{ }^{\circ} \mathrm{C}$ and average rainfall is $4200 \mathrm{~mm}$. $97 \%$ of this watershed is underlain by the Rio Blanco stock, a quartz diorite intrusion of early Tertiary age (45 Ma) (Seiders, 1971; Cox et al., 1977), and 3\% by a quartz-free metavolcanic rock. The Rio Blanco stock is medium to coarse grained and dominated by phenocrysts of quartz and plagioclases and by smaller amounts of biotite, hornblende, chlorite and K-feldspar; accessory minerals are magnetite, sphene, apatite and zircon (White et al., 1998). In the Rio Icacos basin, the regolith profile usually consists of a up to $100 \mathrm{~cm}$ thick soil layer (Buss et al., 2008) and an oxidized unbioturbated saprolite layer which has variable thicknesses ranging from 100 to $800 \mathrm{~cm}$. The saprolite consists of quartz, altered biotite (oxidized and depleted in $\mathrm{K}, \mathrm{Mg}$ and $\mathrm{Fe}$ ), kaolinite and iron oxides (goethite) (White et al., 1998). The quartz diorite bedrock is marked by spheroidal weathering, that loosens and disintegrates the bedrock, creating quartz diorite corestones separated from the saprolite by a succession of concentric layers up to $4 \mathrm{~cm}$ thick each, called rindlets (Turner et al., 2003; Buss et al., 2008). Such alteration 


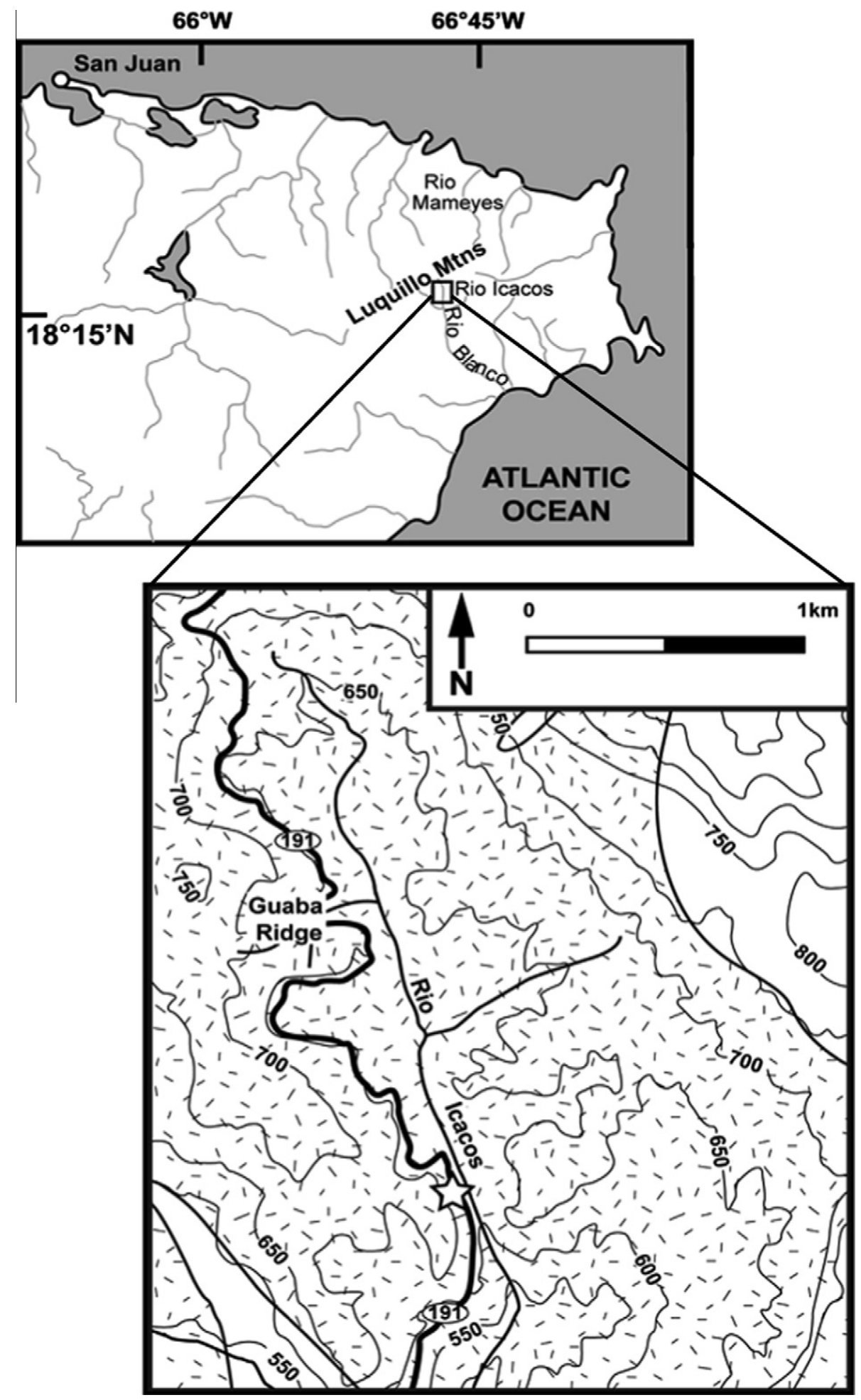

Fig. 1. Location map of the Rio Icacos watershed (star indicates the weathering profile location in the watershed), adapted from Buss et al., 2008.

processes produce weathering profiles, which may contain residual or relict corestones of varying size depending on their vertical position in the saprolite (Fletcher et al., 2006).
For this study, a complete weathering profile developed upward from a corestone exposed at a road cut on Route 191 (details in Buss et al., 2008), was sampled in January 


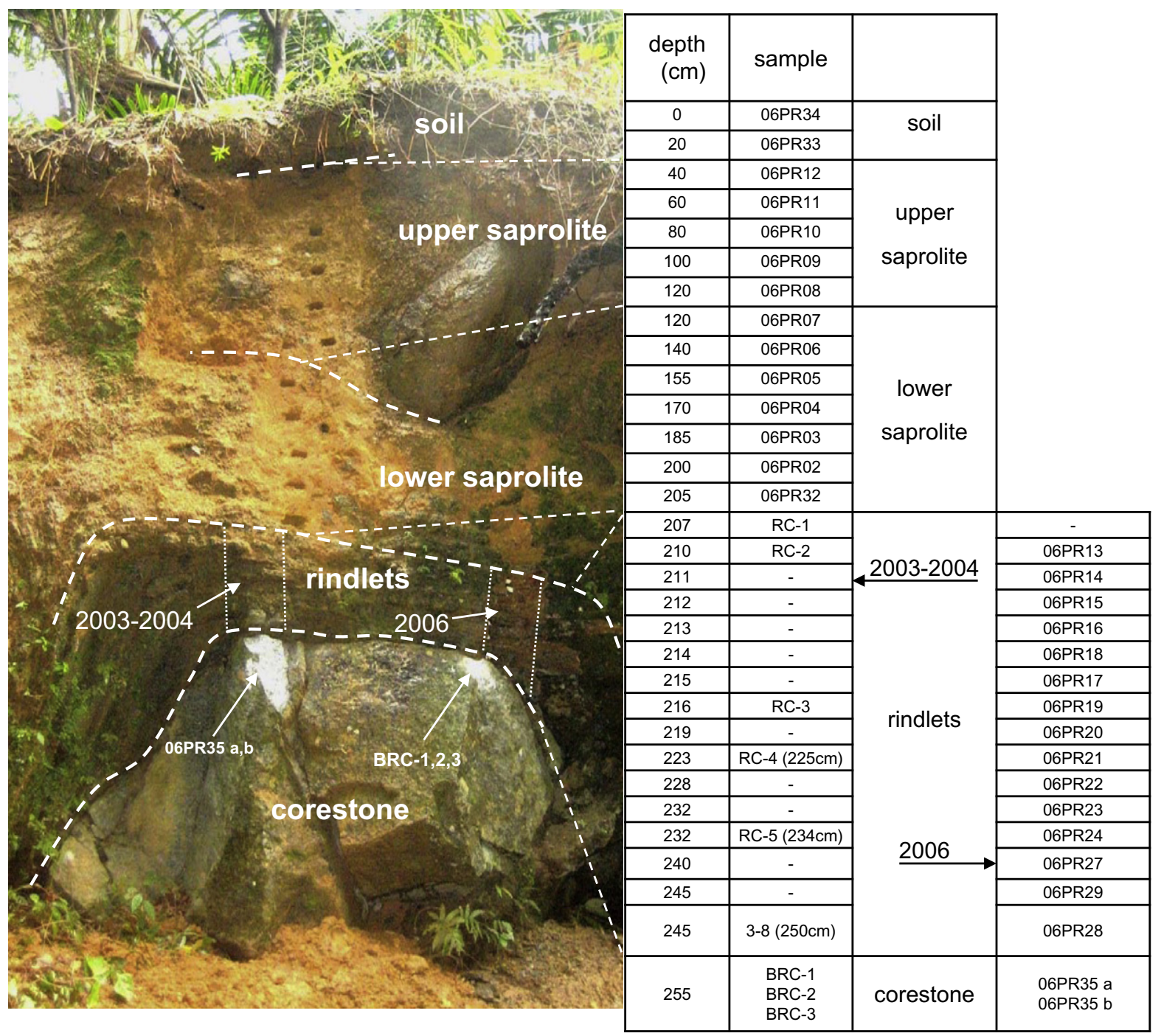

Fig. 2. Sample position along the weathering profile with the name and depth of the different samples. "2003-2004" and "2006" refer to the different sets of sampled rindlets (see text for details).

2006 and March 2008 (Figs. 1 and 2). This profile, hereafter called "outcrop profile", is composed of a $40 \mathrm{~cm}$ thick soil layer overlying a $150 \mathrm{~cm}$ thick saprolite layer which is separated from the corestone by a $\sim 40 \mathrm{~cm}$ thick rindlet zone (Fig. 2). The regolith samples were collected at about $20 \mathrm{~cm}$ intervals; in addition, 15 rindlet samples surrounding the corestone were collected.

Due to the presence of quartz diorite corestones in the upper part of the saprolite, the vertical sampling line through saprolite had to be displaced laterally by about $20 \mathrm{~cm}$ at a depth of $120 \mathrm{~cm}$ (Fig. 2). At this depth the visual characteristic of the saprolite slightly changes from a rather orange color below $120 \mathrm{~cm}$ to a browner one above. In the following, the saprolite is thus subdivided into a lower and upper saprolite layer, respectively (Fig. 2). The rindlets just below the sampling line were previously sampled in 2003 and 2004 and analyzed by Buss et al. (2008). The rindlets collected for the present study originate from the same corestone, but offset $1 \mathrm{~m}$ laterally from those taken before
(Fig. 2). These latter rindlets show mineralogical and chemical differences when compared to the underlying corestone samples (see Electronic Annex EA1). For this reason some of the rindlets sampled in 2003/2004, which are petrologically more similar to the bedrock samples, have also been analyzed in the present study. The position and the nomenclature of all these samples along the profile are given in Fig. 2.

\section{U-SERIES METHODOLOGY AND ANALYTICAL METHODS}

\subsection{U-series modeling}

Determination of regolith production rates from U-series nuclides in weathering profiles relies on the assumption that fractionation among U-series nuclides is only controlled by weathering processes (Dequincey et al., 2002; Chabaux et al., 2003b, 2011; Dosseto et al., 2008; Pelt 
et al., 2008; Ma et al., 2010). These studies have also shown that the mobility of radionuclides during alteration/weathering processes can be expressed in terms of nuclide loss and gain processes. These processes, which are not radioactive, include on one side nuclide losses by mineral dissolution or nuclide desorption from soil minerals and on the other side nuclide gains by illuviation process or dust deposition, or by sorption and co-precipitation of nuclides, especially with Fe-oxides or clay minerals. In such a model scenario, the different processes are not individualized. For each nuclide, the different loss processes are lumped into a single average loss coefficient and the gain processes into a single average gain coefficient. Given the nature of soil formation, nuclide losses and gains are usually considered to be continuous processes. In earlier studies, only $\mathrm{U}$ nuclides were assumed to be mobile whereas $\mathrm{Th}$ nuclides were assumed to be immobile (Chabaux et al., 2003b; Pelt et al., 2008; Ma et al., 2012). However, it has now been illustrated that Th isotopes can also be mobilized under specific weathering conditions (Dosseto et al., 2008; Ma et al., 2010; Rihs et al., 2012). Therefore, equations for Th mobility, similar to those used for $\mathrm{U}$ isotopes, must be incorporated to describe the system. In all these equations the nuclide loss is represented by a first order kinetic rate law and the nuclide gain by a zero order rate law.

Herein, the regolith production rate of the Puerto Rico quartz diorite system will be derived by using such a model; however, in contrast to previous studies, which were mainly based on the use of $\left({ }^{238} \mathrm{U} /{ }^{234} \mathrm{U}\right),\left({ }^{234} \mathrm{U} /{ }^{230} \mathrm{Th}\right)$ and $\left({ }^{230} \mathrm{Th} /{ }^{232} \mathrm{Th}\right)$ activity ratios, the ${ }^{226} \mathrm{Ra}$ nuclide, the direct daughter of ${ }^{230} \mathrm{Th}$, will be incorporated in the model calculations in addition to $\mathrm{U}$ and $\mathrm{Th}$ isotopes. Thus, for this study, the whole ${ }^{238} \mathrm{U}_{-}{ }^{234} \mathrm{U}_{-}{ }^{230} \mathrm{Th}-{ }^{226} \mathrm{Ra}$ disequilibria will be analyzed. The temporal evolution of the number of these atoms of nuclides per gram of sample along with the evolution of the ${ }^{232} \mathrm{Th}$ abundance is then described by the following 5 equations:

$$
\begin{aligned}
\frac{\partial^{238} \mathrm{U}}{\partial t}= & f_{238}{ }^{238} \mathrm{U}_{0}-k_{238}{ }^{238} \mathrm{U}-\lambda_{238}{ }^{238} \mathrm{U} \\
\frac{\partial^{234} \mathrm{U}}{\partial t}= & f_{234}{ }^{234} \mathrm{U}_{0}-k_{234}{ }^{234} \mathrm{U}-\lambda_{234}{ }^{234} \mathrm{U}+\lambda_{238}{ }^{238} \mathrm{U} \\
\frac{\partial^{230} \mathrm{Th}}{\partial t}= & f_{230}{ }^{230} \mathrm{Th}_{0}-k_{230}{ }^{230} \mathrm{Th}-\lambda_{230}{ }^{230} \mathrm{Th}+\lambda_{234}{ }^{234} \mathrm{U} \\
\frac{\partial^{226} \mathrm{Ra}}{\partial t}= & f_{226}{ }^{226} \mathrm{Ra}_{0}-k_{226}{ }^{226} \mathrm{Ra}-\lambda_{226}{ }^{226} \mathrm{Ra} \\
& +\lambda_{230}{ }^{230} \mathrm{Th} \\
\frac{\partial^{232} \mathrm{Th}}{\partial t}= & f_{232}{ }^{232} \mathrm{Th}_{0}-k_{232}{ }^{232} \mathrm{Th}-\lambda_{232}{ }^{232} \mathrm{Th}
\end{aligned}
$$

$\lambda_{i}$ are the decay constants (in $\mathrm{yr}^{-1}$ ) of nuclides $i$ (here ${ }^{238} \mathrm{U}$, ${ }^{234} \mathrm{U},{ }^{230} \mathrm{Th},{ }^{226} \mathrm{Ra}$ and $\left.{ }^{232} \mathrm{Th}\right), k_{i}$ are the first-order rate constants (in $\mathrm{yr}^{-1}$ ) for leaching of nuclides $i$ and $f_{i}$ are the input fluxes (in $\mathrm{yr}^{-1}$ ) of nuclides $i$ gained by the regolith. For simplification, the input fluxes are expressed as a proportion of the number of atoms of nuclides added per year to the initial sample (expressed as $\lambda_{i} \mathrm{~N}_{0}$ ).

Solving the above equation systems yields the theoretical activities of the different nuclides in the sample at time $t$
(Appendix A), which are then used for the calculation of the four independent activity ratios $\left({ }^{238} \mathrm{U} /{ }^{234} \mathrm{U}\right)$, $\left({ }^{230} \mathrm{Th} /{ }^{234} \mathrm{U}\right),\left({ }^{226} \mathrm{Ra} /{ }^{230} \mathrm{Th}\right)$ and $\left({ }^{230} \mathrm{Th} /{ }^{232} \mathrm{Th}\right)$. The nuclides activities and the activity ratios are expressed in function of the mobility parameters $\left(k_{i}, f_{i}\right)$, the initial activities of the different nuclides and the time $t$. In all the above equations $t$ is the time elapsed between the initial state of the sample (or reference weathering state) at $t=0$ and its current state. If the initial time $(t=0)$ corresponds to the onset of weathering, i.e. when the mineral-water interfacial area became large enough that fractionation of the U-series isotopes occurred, then the time $t$ corresponds to the weathering age of the sample (see also Dosseto et al., 2012).

For the determination of the regolith formation rate it is usually assumed that the weathering front progresses along one main direction. Most often, the retained reference state at $t=0$ is given by a sample collected deeper in the weathering profile at a distance $h$ from the considered sample. The nuclide activities in this sample are used as initial activities for Eqs. (1)-(5). The mean regolith production rate $P$ is thus defined by $P=h / \Delta t$, where $\Delta t$ corresponds to the duration time for the sample to move from the state of the reference position to the state of the considered sample position and $\mathrm{h}$ to the distance between these two positions (Ma et al., 2010). If all the mobility parameters used in Eqs. (1)-(5) were known, then the analysis of two samples would be sufficient to determine $\Delta t$ and the regolith production rate. In addition, if the nuclide fractionation can be shown to begin when the sample passes through the alteration front, then the secular equilibrium (activity ratio equal to 1 between nuclides of a same radioactive series) can be considered to be the initial condition of the U-series nuclides in the reference sample at $t=0$, and hence, in theory, only one sample from above the weathering front would be sufficient to determine the regolith production rate. Such an assumption has, however, to be validated by checking that the fresh sample from just below the weathering front is at secular equilibrium. This is actually not always the case (e.g., Ivanovich and Harmon, 1992; Pelt, 2007; Pelt et al., 2008).

Usually, the radionuclide mobility parameters $\left(k_{i}, f_{i}\right)$ are not known and, therefore, the analysis of the radionuclides and the determination of the related radioactive disequilibria within one (or two) sample(s) is(are) not sufficient to calculate the time duration $(\Delta t)$, elapsed for a sample to move from a reference position in the weathering profile to its current position. The classical approach is to collect a series of samples along the weathering direction over a part of the profile for which the mobility parameters can be considered to be constant. The radioactive disequilibria measured in all of these samples are then used to determine (1) the mobility parameters and (2) the age of the different samples relative to the reference sample. If the regolith formation rate is constant over the studied part of the weathering profile, then the regolith production rate can be calculated from the variation of the weathering age of the samples in function of their distance to the reference sample.

Therefore, for the calculation of the regolith production rate a minimum number of samples collected along the weathering profile has to be analyzed. For example, in considering only the U-series nuclide disequilibria 
$\left({ }^{238} \mathrm{U}-{ }^{234} \mathrm{U}-{ }^{230} \mathrm{Th}-{ }^{226} \mathrm{Ra}\right)$, eight mobility parameters have to be determined to use the above differential equations. In the simplest case, where the regolith production rate is assumed to be constant over the studied part of the profile, the system relies on 9 independent parameters (the mobility parameters and the regolith production rate). Their determination requires the knowledge of nine independent relationships between them if none of these parameters are known. The analysis of one sample yields 3 independent values $\left[\left({ }^{234} \mathrm{U} /{ }^{238} \mathrm{U}\right),\left({ }^{230} \mathrm{Th} /{ }^{234} \mathrm{U}\right)\right.$ and $\left({ }^{226} \mathrm{Ra} /{ }^{230} \mathrm{Th}\right)$ activity ratios]. Analysis of at least 4 samples along the weathering direction, representing the system at different evolution stages (one reference sample and three other samples to be dated relative to the reference) is, therefore, necessary to define these 9 parameters. The use of ${ }^{232} \mathrm{Th}$ introduces two additional parameters but provides two additional values $\left[\left({ }^{230} \mathrm{Th} /{ }^{232} \mathrm{Th}\right),\left({ }^{238} \mathrm{U} /{ }^{232} \mathrm{Th}\right)\right.$ activity ratios] for each sample. The same four samples are then characterized by 15 independent relationships, which are theoretically sufficient to determine, in addition to the 10 mobility parameters, the age of the difference samples relative to the reference sample of the other three samples. This duration represents the time elapsed since the sample was in a spatial position equivalent to the position occupied today by the "reference" sample.

In the case of isovolumetric weathering, the regolith propagation rate determined by the above approaches yields directly the propagation rate of the weathering front. Otherwise, in the case of non-isovolumetric weathering, an additional volume correction is required. In the weathering systems studied up to now, such a correction has rarely been applied (Dosseto et al., 2008), as it was assumed or shown that the weathering within the studied systems was more or less isovolumetric. This is probably also the case for the weathering processes occurring in Puerto Rico for the rindlet systems (Turner et al., 2003; Buss et al., 2008) as well as for the saprolites (White et al., 1998; White, 2002).

In the present work, the unknown parameters, i.e. the $k_{i}$ and $f_{i}$ mobility parameters of each nuclide $i$, the average integrated regolith production rate $P$, or, the age of the different samples relative to the reference sample (if the number of independent data is large enough) is determined by a bound constrained optimization algorithm built for solving such non-linear least-squares problems (e.g., Byrd et al., 1995; Zhu and Byrd, 1997; Morales and Nocedal, 2011). Details are given in Appendix A. This kind of approach has been successfully implemented in the parameterization of non-linear weakly parameterized problems (di Chiara Roupert et al., 2010). Similar to other studies (Chabaux et al., 2003b; Dosseto et al., 2008, 2012; Ma et al., 2010, 2012), one has to find a range of possible parameters, which fit best the activity ratios in a way that minimizes the difference between observed and modeled values (i.e. the different activity ratios).

It is important to note that such an approach implicitly assumes that it is possible to find a zone within the weathering profile where weathering progresses along one main direction and where the different model parameters (mobility parameters and in some cases production rates) can be considered to be constant. As shown in the following sections, the information provided by mineralogical and geochemical data will help to decipher whether or not such assumptions are geochemically consistent with the studied Puerto Rico profile.

\subsection{Analytical techniques}

The mineralogical and geochemical analyses and the isotope determinations $\left({ }^{87} \mathrm{Sr} /{ }^{86} \mathrm{Sr},{ }^{143} \mathrm{Nd} /{ }^{144} \mathrm{Nd}\right.$, U-series nuclides) of the samples collected at the outcrop profile were performed at the University of Strasbourg, France. Soil and saprolite samples were sieved at $2 \mathrm{~mm}$ and the $<2 \mathrm{~mm}$ subsamples were finely powdered with an agate disk mill to ensure a complete sample digestion. The rindlets sampled in 2006, hereafter named 2006 rindlets, were drilled by a $20 \mathrm{~mm}$ diameter diamond-steel tube with diamond particles. The obtained subsamples were crushed using a hydraulic press and finely powdered following the above procedure. For the rindlet samples collected in 2003 and 2004, named 2003-2004 rindlets, all pieces were finely powdered following the above procedure.

Major and trace element concentrations, ${ }^{87} \mathrm{Sr} /{ }^{86} \mathrm{Sr}$ isotopic ratio and U-Th-Ra disequilibria were analyzed for almost all outcrop profile samples, while $\mathrm{Nd}$ isotope ratios were determined for only a few samples (see Tables 1 and 2). In addition, the mineralogical composition of one quartz diorite corestone sample, one 2006 rindlet and 3 saprolite samples were qualitatively determined by powdered X-ray diffraction (XRD Brüker, D5000).

Major and trace element concentrations were determined by inductively-coupled plasma atomic emission spectrometer (ICP-AES) and by inductively-coupled plasma mass spectrometry (ICP-MS), respectively, after lithium metaborate fusion. The analytical uncertainty is $<3 \%$ for major element concentrations and $<10 \%$ for trace element concentrations at $2 \sigma$ (Dequincey et al., 2006).

For ${ }^{87} \mathrm{Sr} /{ }^{86} \mathrm{Sr}$ isotopic ratio and ${ }^{238} \mathrm{U}_{-}{ }^{234} \mathrm{U}-{ }^{230} \mathrm{Th}-{ }^{226} \mathrm{Ra}$ radioactive disequilibria measurements, about $200 \mathrm{mg}$ of the powdered samples were spiked with a mixed ${ }^{233} \mathrm{U}_{-}{ }^{229} \mathrm{Th}$ tracer and a ${ }^{228} \mathrm{Ra}$ tracer purified from $\mathrm{Th}$. The tracers were regularly calibrated by Thermal Ionization Mass Spectrometry (TIMS) with the AThO rock standard. The sample-spike mix is then dissolved using a three-step procedure with $\mathrm{HNO}_{3}-\mathrm{HF}$ acids, $\mathrm{HClO}_{4}$ and $\mathrm{HCl}-\mathrm{H}_{3} \mathrm{BO}_{3}$ acids (Granet et al., 2007, 2010; Pelt et al., 2008; Ma et al., 2010).

Separation and purification of the $U$ and Th fractions were achieved by using conventional anion exchange chromatography (Dequincey et al., 2002; Granet et al., 2007; Pelt et al., 2008). The Ra fraction was collected during the first step of the U-Th separation procedure, and then purified using a procedure adapted from the previous published separation protocols (Chabaux and Allègre, 1994; Chabaux et al., 1994; Ghaleb et al., 2004; Chmeleff, 2005; Pelt, 2007). It involved three successive chromatographic separations: one for separating the $\mathrm{Ra}-\mathrm{Ba}$ fraction from the main major elements and from most of Rare Earth Elements (REE), another one to enhance $\mathrm{Ra}-\mathrm{Ba}$ purification (especially from $\mathrm{Ca}$ but also $\mathrm{Sr}$ ), and a last one to separate 
Table 1

Chemical composition of the samples. Major elements are given in oxide wt. $\%$ and trace elements in ppm.

\begin{tabular}{|c|c|c|c|c|c|c|c|c|c|c|c|c|c|c|c|c|c|c|c|c|c|c|c|c|c|c|c|c|c|c|}
\hline & Depth & & LOI & $\mathrm{SiO}_{2}$ & ${ }_{2} \mathrm{Al}_{2} \mathrm{O}_{3}$ & $\mathrm{MgC}$ & $\mathrm{CaO}$ & $\mathrm{Fe}_{2} \mathrm{O}_{3}$ & $\mathrm{MnO}$ & $\mathrm{TiO}_{2}$ & $\mathrm{Na}_{2} \mathrm{O}$ & $\mathrm{K}_{2} \mathrm{O}$ & $\mathrm{P}_{2} \mathrm{O}_{5}$ & CWI & $\mathrm{Sr}$ & $\mathrm{Zr}$ & $\mathrm{Hf} \mathrm{La}$ & $\mathrm{Ce}$ & $\operatorname{Pr}$ & $\mathrm{Nd}$ & $\mathrm{Sm}$ & $\mathrm{Eu}$ & Gd & $\mathrm{Tb}$ & Dy & Ho & $\mathrm{Er}$ & $\mathrm{Tm}$ & $\mathrm{Yb}$ & $\mathrm{Lu}$ \\
\hline & & & in wt. & & & & & & & & & & & & ppm & & & & & & & & & & & & & & & \\
\hline \multirow[t]{5}{*}{ Corestones } & 255 & 06PR35a & 0.6 & 59.1 & 17.9 & 2.55 & 7.19 & 7.19 & 0.15 & 0.54 & 3.10 & 0.94 & 0.13 & 17.3 & 259 & 112 & 2.77 .4 & 16.6 & 52.4 & 10.7 & 72.9 & 0.88 & 2.2 & 0.46 & 63.5 & 0.78 & 2.1 & 0.38 & 2.3 & 0.38 \\
\hline & 255 & 06PR 35b & - & 57.2 & 17.8 & 2.57 & 7.82 & 7.72 & 0.15 & .54 & & 64 & 0.13 & 18.6 & 246 & 96 & & & 2.3 & 0.7 & 72.9 & 0.89 & 3.2 & 0.50 & 3.4 & 0.78 & 2.2 & 0.40 & 2.4 & 0.36 \\
\hline & 255 & BRC-1 & 0.74 & 59.3 & 18.8 & 2.51 & 6.75 & 6.56 & 0.16 & 0.49 & 21 & 90 & 0.09 & 18.1 & 291 & 3 & 4.67 & & 2.7 & .4 & 43.3 & 1.0 & 3.0 & .58 & 4.0 & 0.89 & 92.4 & 0.42 & 2.7 & 0.45 \\
\hline & 255 & BRC-2 & & 60.2 & 17.7 & 2.52 & 6.52 & 6.51 & 0.15 & 0.49 & 3.12 & 74 & 0.13 & 6.8 & 262 & 5 & & & 2.3 & .9 & 93.0 & 0.91 & 2.8 & 0.52 & 23.6 & .82 & 2.2 & 0.38 & 2.5 & 0.39 \\
\hline & 255 & BRC-5 & 0.49 & 58.9 & 18.4 & 2.76 & 7.07 & 7.04 & 0.15 & 0.51 & 3.31 & 0.79 & 0.23 & 17.2 & 252 & 109 & & & 2.6 & 12.0 & 03.2 & 0.90 & 2.8 & 0.55 & 53.8 & 0.85 & 52.3 & 0.39 & 2.6 & 0.40 \\
\hline \multirow{6}{*}{$\begin{array}{l}2003-2004 \\
\text { rindlets }\end{array}$} & 250 & $3-8$ & & 61.2 & & 2.97 & 6.39 & 7.87 & 0.18 & 0.59 & 2.97 & 0.68 & 0.15 & 15.3 & 268 & & & & 2.2 & 11.2 & 23.2 & 0.97 & 3.6 & 0.61 & 14.0 & 0.86 & 62.7 & 0.40 & 2.8 & 0.47 \\
\hline & 234 & RC-5 & & 58.2 & 17.7 & 2.97 & 6.21 & 7.93 & 0.18 & 0.59 & 3.03 & 0.85 & & 16.0 & 272 & 144 & & & 2.9 & 13.7 & 73.6 & 1.1 & 4.1 & 0.67 & 74.5 & 0.94 & 42.9 & 0.45 & 3.1 & 0.53 \\
\hline & 225 & RC-4 & 1.24 & 59.8 & 18.1 & 2.73 & 5.91 & 7.32 & 0.16 & 0.56 & 3.03 & 0.77 & 0.17 & 15.8 & 255 & 119 & 3.07 & & 52.4 & 11.5 & 53.1 & 0.99 & 3.5 & 0.58 & 83.9 & 0.81 & 12.5 & 0.39 & 2.6 & 0.46 \\
\hline & 216 & RC-3 & & 56.7 & 17.9 & 3.21 & 5.76 & 9.06 & 0.19 & 0.67 & 2.91 & 0.81 & 0.14 & 16.9 & 237 & 84 & & & 2.6 & 12.8 & 3.4 & 1.0 & 3.9 & 0.64 & 4.2 & 0.89 & 92.8 & 0.44 & 3.0 & 0.50 \\
\hline & 210 & RC-2 & 1.69 & 58.1 & 17.2 & 3.16 & 5.72 & 8.20 & 0.19 & 0.59 & 2.79 & 0.69 & 15 & 16.2 & 233 & 90 & & & 2.5 & 12.5 & 53.5 & 1.0 & 4.0 & 0.65 & 54.4 & 0.92 & 22.9 & 0.45 & 3.0 & 0.52 \\
\hline & 207 & RC-1 & 1.66 & 59.9 & 18.4 & 3.00 & 5.66 & 7.84 & 0.17 & 0.59 & 2.96 & 0.67 & 0.16 & 16.2 & 242 & 117 & 2.96 & & 2.5 & 12.1 & 3.3 & 1.0 & 3.8 & 0.63 & 34.1 & 0.88 & 8.7 & 0.43 & 2.9 & 0.50 \\
\hline \multirow[t]{7}{*}{ Lower saprolite } & 205 & 06PR32 & 5.94 & 53.3 & & & 4.54 & & 0.19 & 0.66 & 1.91 & & & & 106 & 71 & & & 2.6 & 12.5 & 53.7 & & 3.1 & 0.59 & 4.4 & 000 & 92.6 & 0.44 & 3.0 & 0.48 \\
\hline & 200 & 6PR02 & .6 & 49.0 & 20.9 & .76 & 0.68 & 13.5 & 0.14 & 0.93 & 0.22 & 0.41 & 0.03 & 51 & 7.0 & 115 & 3.26 & 9 & 2.3 & 10.6 & 63.0 & 0.79 & 2.8 & 0.48 & 3.3 & 0.71 & 11.9 & 0.34 & 2.3 & 0.35 \\
\hline & 185 & 06PR03 & 1.3 & 53.1 & 22.5 & 0.72 & 0.09 & 10.1 & 0.06 & 0.73 & 0.14 & 0.27 & 0.03 & 50 & 5.3 & 148 & 3.84. & 21.9 & & 6.5 & 51.9 & 0.53 & 1.6 & 0.30 & 2.0 & 0.43 & 31.2 & 0.21 & 1.4 & 0.24 \\
\hline & 170 & 06PR04 & 0.0 & 56.2 & 20.0 & 0.29 & 0.05 & 11.0 & 0.06 & 0.68 & & 0.23 & 0.04 & 46 & 3.4 & +163 & 3.82 .7 & 6.1 & 0.71 & 2.9 & 0.82 & 0.25 & 0.72 & 0.10 & 0.97 & 0.22 & 20.62 & 0.11 & 0.81 & 0.13 \\
\hline & 155 & 06PR & 11.5 & 51.7 & 22.4 & 1.23 & 0.36 & 10.9 & 0.08 & 0.73 & & 0.30 & 0.04 & 50 & 6.6 & 5165 & 4.35 .3 & 14.6 & 1.6 & 7.2 & 2.0 & 0.51 & 1.8 & 0.31 & 2.4 & 0.53 & 31.5 & 0.27 & 1.7 & 0.29 \\
\hline & 140 & 06PR06 & 11.8 & 52.0 & 21.8 & 0.56 & 0.12 & 11.7 & 0.06 & 0.71 & 0.16 & 0.21 & 0.04 & 51.7 & 10.0 & 146 & 3.74 .2 & 8.9 & 1.2 & 4.9 & 91.4 & 0.37 & 0.98 & 0.17 & 1.5 & 0.32 & 20.90 & 0.16 & 1.1 & 0.18 \\
\hline & 120 & 06PR07 & 12.0 & 49.2 & 22.8 & 0.79 & 0.50 & 12.1 & 0.08 & 0.85 & 0.18 & 0.20 & 0.04 & 53.4 & 6.1 & 153 & 3.82 .7 & 6.1 & 0.76 & 3.3 & 31.1 & 0.25 & 0.76 & 0.14 & 1.4 & 0.30 & 0.85 & 0.16 & 1.0 & 0.17 \\
\hline \multirow[t]{5}{*}{ Upper saprolite } & 120 & 06PR08 & & 63.6 & 15.2 & 1.32 & 0.91 & 9.00 & 0.09 & 0.64 & 0.44 & 0.29 & 0.03 & 37.2 & 21.0 & 217 & 5.87 .1 & 10.2 & & 6.6 & 61.9 & 0.39 & 1.7 & 0.30 & 2.3 & 0.52 & 21.5 & 0.27 & 1.8 & 0.30 \\
\hline & 100 & & & 67 & & & 0.2 & & 0.0 & 9 & & & & 35 & & 3259 & 6.33 .4 & & & & & & & & & & & 0.1 & 0.8 & 0. \\
\hline & 80 & & & 74.7 & 10.1 & 0.39 & 0.34 & 6.50 & 0.04 & 0.51 & 0.25 & 0.19 & 0.03 & 28.1 & & 5249 & 6.23 .3 & 6.5 & 82 & 3.3 & 0 & 0.19 & 0.72 & 0.10 & & 0.23 & & 0.13 & 0.9 & 0.18 \\
\hline & 60 & & & 74.4 & 10.0 & 0.42 & 0.35 & & 0.04 & 0.52 & & & & 29.8 & 13.3 & 3269 & 6.63 .5 & 6.8 & 0.85 & 3.4 & 0.84 & 0.20 & 0.80 & 0.10 & 0.98 & 0.22 & & 0.13 & 0.92 & 0.17 \\
\hline & 40 & 06PR12 & 9.14 & 67.2 & 13.3 & 0.66 & 0.74 & 6.76 & 0.06 & 0.57 & 0.46 & 0.28 & 0.04 & 37.2 & 24.6 & 5233 & 5.73 .6 & 7.9 & 1.0 & 4.3 & 1.1 & 0.29 & 0.98 & 0.20 & 1.3 & 0.30 & 0.84 & 0.16 & 1.1 & 0.19 \\
\hline \multirow[t]{2}{*}{ Soil } & 20 & 06PR33 & 8.78 & 62.4 & 15.2 & 0.87 & 0.90 & 9.43 & 0.08 & 0.65 & 0.49 & 0.28 & 0.05 & 39. & 24.8 & 174 & 4.53 .6 & & & .0 & & 0.36 & & & 1.7 & 0.37 & 71.0 & 0.19 & 1.3 & 0.22 \\
\hline & 0 & 06PR34 & 16.9 & 53.0 & 17.2 & 0.74 & 0.63 & 9.12 & 0.08 & 0.64 & 0.36 & 0.26 & 0.08 & 55.9 & 19.2 & 2182 & 4.34 .0 & 9.9 & 1.1 & 4.3 & & 0.31 & 0.65 & 0.12 & 1.3 & 0.31 & 10.87 & 0.16 & 1.1 & 0.19 \\
\hline
\end{tabular}


Table 2

$\mathrm{U}, \mathrm{Th},{ }^{226} \mathrm{Ra}$ concentrations, U/Th elemental ratios, $\mathrm{U}$ and Th activity ratios, $\left({ }^{230} \mathrm{Th} /{ }^{234} \mathrm{U}\right),\left({ }^{226} \mathrm{Ra} /{ }^{230} \mathrm{Th}\right)$ ratios, Sr isotopes ratios, $\varepsilon_{\mathrm{Nd}}$ values.

\begin{tabular}{|c|c|c|c|c|c|c|c|c|c|c|c|c|c|c|c|}
\hline & $\begin{array}{l}\text { Depth } \\
(\mathrm{cm})\end{array}$ & $\begin{array}{l}\text { Sample } \\
\text { name }\end{array}$ & $\begin{array}{l}\text { Date of } \\
\text { sampling }\end{array}$ & $\begin{array}{l}\mathrm{U} \\
(\mathrm{ppm})\end{array}$ & $\begin{array}{l}\text { Th } \\
(\mathrm{ppm})\end{array}$ & $\begin{array}{l}{ }^{226} \mathrm{Ra} \\
(\mathrm{fg} / \mathrm{g})\end{array}$ & $\begin{array}{l}\mathrm{U} / \\
\mathrm{Th}\end{array}$ & $\left({ }^{234} \mathrm{U} /{ }^{238} \mathrm{U}\right)$ & $\left({ }^{230} \mathrm{Th} /{ }^{232} \mathrm{Th}\right)$ & $\left({ }^{238} \mathrm{U} /{ }^{232} \mathrm{Th}\right)$ & $\left({ }^{230} \mathrm{Th} /{ }^{238} \mathrm{U}\right)$ & $\left({ }^{230} \mathrm{Th} /{ }^{234} \mathrm{U}\right)$ & $\left({ }^{226} \mathrm{Ra} /{ }^{230} \mathrm{Th}\right)$ & $\varepsilon_{\mathrm{Nd}}$ & ${ }^{87} \mathrm{Sr} /{ }^{86} \mathrm{Sr}$ \\
\hline \multirow[t]{7}{*}{ Corestones } & 255 & 06PR35a & 2006 & 0.336 & 1.115 & 147 & 0.301 & 1.023 & 1.165 & 0.914 & 1.274 & 1.245 & 1.019 & 6.1 & 0.70397 \\
\hline & 255 & 06PR35b & 2006 & 0.330 & 0.970 & 141 & 0.340 & 1.022 & 1.313 & 1.032 & 1.271 & 1.244 & 0.997 & - & 0.70400 \\
\hline & 255 & BRC-1 & 2008 & 0.334 & 0.975 & 141 & 0.343 & 1.013 & 1.303 & 1.040 & 1.254 & 1.238 & 0.995 & - & 0.70432 \\
\hline & 255 & BRC-2 & 2008 & 0.275 & 0.793 & 120 & 0.347 & 1.019 & 1.453 & 1.052 & 1.381 & 1.355 & 0.934 & 7.2 & 0.70440 \\
\hline & 255 & BRC-5 & 2008 & 0.325 & 1.052 & 139 & 0.309 & 1.031 & 1.150 & 0.938 & 1.226 & 1.189 & 1.028 & - & - \\
\hline & 250 & $3-8$ & 2003 & 0.218 & 0.574 & 95.2 & 0.380 & 1.020 & 1.434 & 1.152 & 1.244 & 1.220 & 1.040 & 7.2 & 0.70391 \\
\hline & 234 & RC-5 & 2004 & 0.408 & 1.201 & 156 & 0.340 & 1.020 & 1.113 & 1.031 & 1.080 & 1.058 & 1.051 & - & - \\
\hline 2003-2004 & 225 & $\mathrm{RC}-4$ & 2004 & 0.407 & 0.971 & 144 & 0.419 & 1.022 & 1.289 & 1.272 & 1.013 & 0.991 & 1.038 & - & - \\
\hline \multirow[t]{5}{*}{ Rindlets } & 216 & $\mathrm{RC}-3$ & 2004 & 0.508 & 0.970 & 181 & 0.524 & 1.024 & 1.610 & 1.589 & 1.013 & 0.989 & 1.044 & - & - \\
\hline & 210 & RC-2 & 2004 & 0.439 & 0.746 & 156 & 0.588 & 1.018 & 1.781 & 1.786 & 0.997 & 0.980 & 1.057 & - & - \\
\hline & 207 & RC-1 & 2004 & 0.390 & 0.820 & 141 & 0.476 & 1.017 & 1.428 & 1.443 & 0.990 & 0.973 & 1.082 & 6.8 & 0.70393 \\
\hline & 205 & 06PR32 & 2006 & 0.570 & 1.243 & 170 & 0.459 & 1.022 & 1.388 & 1.392 & 0.997 & 0.976 & 0.886 & - & 0.70404 \\
\hline & 200 & 06PR02 & 2006 & 0.838 & 2.034 & 266 & 0.412 & 1.019 & 1.272 & 1.250 & 1.017 & 0.998 & 0.924 & 5.2 & 0.70887 \\
\hline \multirow{7}{*}{$\begin{array}{l}\text { Lower } \\
\text { saprolite }\end{array}$} & 185 & 06PR03 & 2006 & 0.866 & 2.695 & 284 & 0.321 & 1.021 & 1.114 & 0.975 & 1.142 & 1.119 & 0.851 & 3.0 & 0.71227 \\
\hline & 170 & 06PR04 & 2006 & 0.689 & 1.298 & 243 & 0.531 & 1.033 & 1.537 & 1.611 & 0.954 & 0.924 & 1.094 & 3.2 & 0.71098 \\
\hline & 155 & 06PR05 & 2006 & 0.886 & 2.871 & 337 & 0.309 & 1.021 & 1.156 & 0.936 & 1.235 & 1.209 & 0.912 & - & 0.71096 \\
\hline & 140 & 06PR06 & 2006 & 0.808 & 2.389 & 297 & 0.338 & 1.029 & 1.150 & 1.026 & 1.121 & 1.089 & 0.971 & 2.7 & 0.71215 \\
\hline & 120 & 06PR07 & 2006 & 0.646 & 1.399 & 218 & 0.462 & 1.018 & 1.400 & 1.401 & 0.999 & 0.981 & 0.999 & - & 0.70850 \\
\hline & 120 & 06PR08 & 2006 & 0.707 & 2.027 & 289 & 0.349 & 1.029 & 1.308 & 1.058 & 1.236 & 1.201 & 0.980 & 4.1 & 0.70598 \\
\hline & 100 & 06PR09 & 2006 & 0.641 & 1.427 & 209 & 0.449 & 1.030 & 1.434 & 1.363 & 1.052 & 1.021 & 0.917 & - & 0.70844 \\
\hline \multirow{3}{*}{$\begin{array}{l}\text { Upper } \\
\text { saprolite }\end{array}$} & 80 & 06PR 10 & 2006 & 0.510 & 1.051 & 154 & 0.485 & 1.045 & 1.452 & 1.472 & 0.986 & 0.943 & 0.907 & 0.2 & 0.70716 \\
\hline & 60 & 06PR11 & 2006 & 0.510 & 1.056 & 151 & 0.483 & 1.049 & 1.433 & 1.466 & 0.977 & 0.932 & 0.896 & 0.8 & 0.70682 \\
\hline & 40 & 06PR12 & 2006 & 0.602 & 1.279 & 190 & 0.471 & 1.042 & 1.415 & 1.428 & 0.991 & 0.951 & 0.945 & 2.5 & 0.70540 \\
\hline \multirow[t]{2}{*}{ Soil } & 20 & 06PR33 & 2006 & 0.578 & 1.285 & 180 & 0.450 & 1.026 & 1.379 & 1.365 & 1.010 & 0.984 & 0.914 & 4.7 & 0.70499 \\
\hline & 0 & 06PR34 & 2006 & 0.607 & 1.375 & 176 & 0.441 & 1.022 & 1.353 & 1.340 & 1.010 & 0.988 & 0.850 & 3.9 & 0.70596 \\
\hline Leeves & 0 & 06PR36 & 2006 & - & - & - & - & - & - & - & - & - & - & -2.9 & 0.70825 \\
\hline Branch & 0 & 06PR37 & 2006 & - & - & - & - & - & - & - & - & - & - & -1.2 & 0.70713 \\
\hline
\end{tabular}


Ra from Ba. U, Th, ${ }^{226} \mathrm{Ra}$ concentrations and $\mathrm{U}$ and $\mathrm{Th}$ isotopic ratios were analyzed in Strasbourg (LHyGeS) by TIMS on a Thermo Scientific Triton.

$\mathrm{U}$ concentrations and isotopic ratios were measured by using a single $\mathrm{Re}$ filament procedure with graphite. $\left({ }^{234} \mathrm{U} /{ }^{238} \mathrm{U}\right)$ activity ratios were calculated using the measured ${ }^{234} \mathrm{U} /{ }^{235} \mathrm{U}$ ratios and assuming a constant ${ }^{238} \mathrm{U} /{ }^{235} \mathrm{U}$ ratio of 137.88, with the decay constant in Akovali (1994) and Cheng et al. (2000).

The accuracy and reproducibility of $\left({ }^{234} \mathrm{U} /{ }^{238} \mathrm{U}\right)$ were controlled by analyzing the HU1 secular equilibrium standard solution. During the period of data acquisition (2007-2008), the mean $\left({ }^{234} \mathrm{U} /{ }^{238} \mathrm{U}\right)$ of the HU1-standard was $1.001 \pm 0.005(n=10 ; 2 \sigma)$. The reproducibility of $\mathrm{U}$ concentrations and activity ratios was checked by duplicate analyses of 4 samples and was better than $1 \%$ and $0.5 \%$, respectively.

Th concentrations and isotopic ratios were determined using a double Re-Re filament assembly. ${ }^{230} \mathrm{Th}$ and ${ }^{229} \mathrm{Th}$ were measured on the central SEM detector and ${ }^{232} \mathrm{Th}$ on a Faraday cup using the static collection mode. During the course of this study, the Th isotopic ratio measurements were assessed by analyzing the BRGM Th105 standard solution (Innocent et al., 2004 ), ${ }^{232} \mathrm{Th} /{ }^{230} \mathrm{Th}=217817 \pm 1220$ $(n=7,2 \sigma)$. The reproducibility of Th concentrations and activity ratios was checked by duplicate analyses of 4 samples and was better than $1.3 \%$ and $1.1 \%$, respectively.

${ }^{226} \mathrm{Ra}$ concentrations were measured by using a single Re filament procedure with $\mathrm{Ta}_{2} \mathrm{O}_{5}$, following a protocol adapted from Chabaux et al. (1994). ${ }^{226} \mathrm{Ra} /{ }^{228} \mathrm{Ra}$ ratio was measured in peak jumping mode on a secondary electron multiplier associated with a pulse counting system at a temperature of $\sim 1270{ }^{\circ} \mathrm{C}$ with a beam intensity between 100 and $200 \mathrm{cps}$ for the minor isotope ${ }^{228} \mathrm{Ra}$. The ${ }^{228} \mathrm{Ra}$ decay of the spike was monitored by regular measurement of its ${ }^{226} \mathrm{Ra} /{ }^{228} \mathrm{Ra}$ ratio, and the ${ }^{226} \mathrm{Ra}$ concentration of the spike was calibrated with AThO rock standard assuming to be at secular equilibrium for ${ }^{226} \mathrm{Ra}-{ }^{230} \mathrm{Th}$ isotopes. The reproducibility of ${ }^{226} \mathrm{Ra}$ concentration was checked by duplicate analyses of 4 samples and was better than $1.3 \%$.

The $\mathrm{Sr}$ and $\mathrm{Nd}$ fractions were collected during the first stage of the chemical Ra separation. The Sr fraction was purified using Eichrom's Sr Resin according to the protocol developed in the lab (Lahd Geagea et al., 2007). ${ }^{87} \mathrm{Sr} /{ }^{86} \mathrm{Sr}$ ratios were measured on $<600 \mathrm{ng} \mathrm{Sr}$ samples with a VG Sector mass spectrometer (TIMS) using a dynamic multicollection procedure. Replicate measurements of the SRM987 standard (NIST, USA) over the analysis period gave a mean ${ }^{87} \mathrm{Sr} /{ }^{86} \mathrm{Sr}$ ratio of $0.71027 \pm 2(n=11 ; 2 \sigma)$.

The Nd fraction was separated from the other elements using Eichrom's TRU Resin in series with Eichroms Ln Resin following a procedure adapted from those already published (Pin and Zalduegui, 1997; Stille et al., 2009). The Nd isotopic compositions were determined on a Neptune instrument MC-ICP-MS. The Merck solution yields ${ }^{143} \mathrm{Nd} /{ }^{144} \mathrm{Nd}=0.51172 \pm 2(2 \sigma, n=29)$ and the La Jolla standard analysis gave a mean ${ }^{143} \mathrm{Nd} /{ }^{144} \mathrm{Nd}$ ratio of $0.51184 \pm 1(2 \sigma, n=6)$.

The total procedure blanks were $<15 \mathrm{pg}$ for $\mathrm{U}, 300 \mathrm{pg}$ for $\mathrm{Th}, 0.07 \mathrm{fg}$ for $\mathrm{Ra}, 0.5 \mathrm{ng}$ for $\mathrm{Sr}$ and $<14 \mathrm{pg}$ for $\mathrm{Nd}$ which is negligible $(<1 \%)$ compared to the amount of elements analyzed in the studied samples.

\section{RESULTS AND FIRST INTERPRETATIONS}

\subsection{Mineralogical and petrological observations through the outcrop profile}

Weathering of the quartz diorite has been shown to develop relatively spheroidal corestones that are separated by 40 - to $50-\mathrm{cm}$ thick sets of rindlets of approximately $2 \mathrm{~cm}$ thickness each. Corestones seem to form on top of one another in a vertical profile (Turner et al., 2003; Fletcher and Brantley, 2010). At our sampling site, we sampled the lowermost visible corestone, its rindlets, and the saprolite above the rindlets. However, two corestones higher in the profile can be seen (Fig. 2). The profile was therefore considered to be physically structured and was subdivided into five different compartments (Fig. 2): the lowermost quartz diorite corestone, the rindlet zone, the lower saprolite, the upper saprolite, and the soil. The upper and lower saprolite zones were delineated roughly as the upper part where two visible corestones are embedded within the saprolite and the lower part directly above the lowermost corestone. The structure of the profile can arise from spheroidal weathering, which proceeds along preferential surfaces of water circulation in the rock, inherited from the 3D network of preexisting bedrock joint planes. This isolates progressively residual corestones in the saprolite. However, the corestones embedded within the upper saprolite are smaller than the lowermost corestone and do not have rindlet sequences associated with them, although surficial fractures indicate incipient rindlet formation. These corestones, along with the upper saprolite, could have been transported during a landslide and deposited on top of the lower saprolite profile, rather than be formed in situ by spheroidal weathering.

The lowermost quartz diorite corestone mainly consists of plagioclase, quartz, hornblende and biotite, consistent with previous analyses of the Rio Blanco quartz diorite (Seiders, 1971; Murphy et al., 1998; White et al., 1998; Turner et al., 2003; Buss et al., 2008). In addition, traces of kaolinite were detected in some of the samples. This is consistent with the observation of Fe-rich chlorite and kaolinite resulting from biotite alteration in the bedrock (Murphy et al., 1998; White et al., 1998; Buss et al., 2008).

As mentioned in the previous sections, the rindlet samples collected in 2006 have petrological and mineralogical characteristics different from those of the corestone samples and the 2003-2004 rindlets. The 2006 rindlets contain the same minerals as the corestone but with larger quantities of mafic minerals such as amphibole and the plagioclase is less abundant and finer grained than in the corestone samples (see Electronic Annex EA1). This explains the darker color of these rindlets compared to those of the corestone and of the 2003-2004 rindlets. These rindlets were found inappropriate for dating by the U-Th-Ra methods. They will not be discussed in the following. Data including U-series nuclide composition are given in Electronic Annex EA, which also explains why they cannot be used for the 
dating issue. This example will be certainly important to keep in mind in future studies that will seek to apply the U-series nuclides methodology to recover time information from their analysis in a weathering profile.

The saprolite mineralogy is similar to that reported previously for the nearby LG-1 profile (White et al., 1998): quartz, goethite, weathered biotite and kaolinite. However, as described above, the saprolite sampled in the present study can be subdivided into two parts. Our observations indicate that these two zones are marked by some mineralogical differences: the upper saprolite (Fig. 2) is enriched in primary minerals compared to the lower part and has a pla-
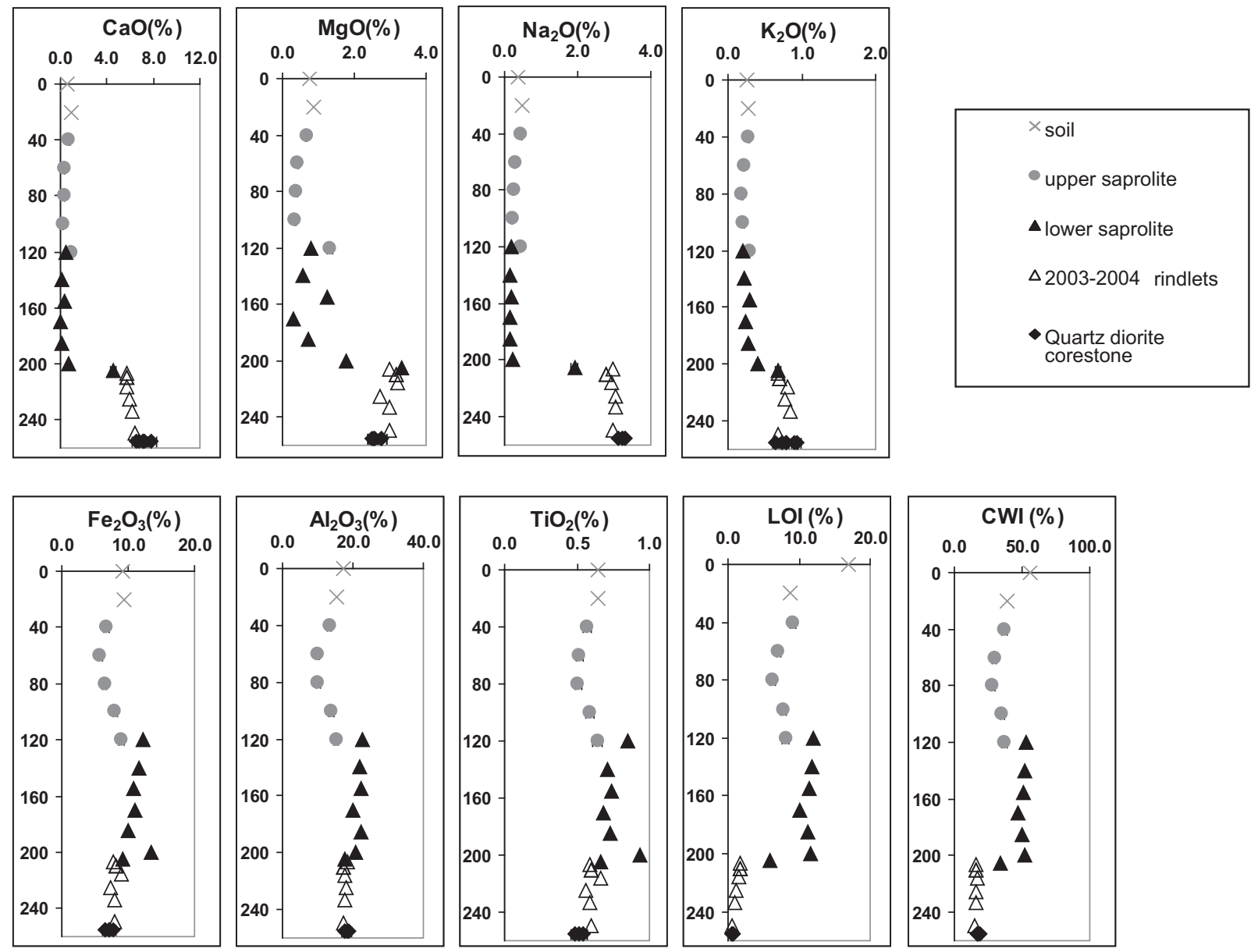

Fig. 3. Depth variation of the major element concentration along the weathering profile (major element concentrations are given in weight percent of oxides; LOI for Loss-on-ignition (in wt.\%); CWI: chemical weathering index defined by $\mathrm{CWI} \%=\left[\left(\mathrm{Al}_{2} \mathrm{O}_{3}+\mathrm{Fe}_{2} \mathrm{O}+\mathrm{TiO}_{2}+-\right.\right.$ $\mathrm{LOI} \%$ )/sum of major oxides $\%] \times 100($ Sueoka, 1988).

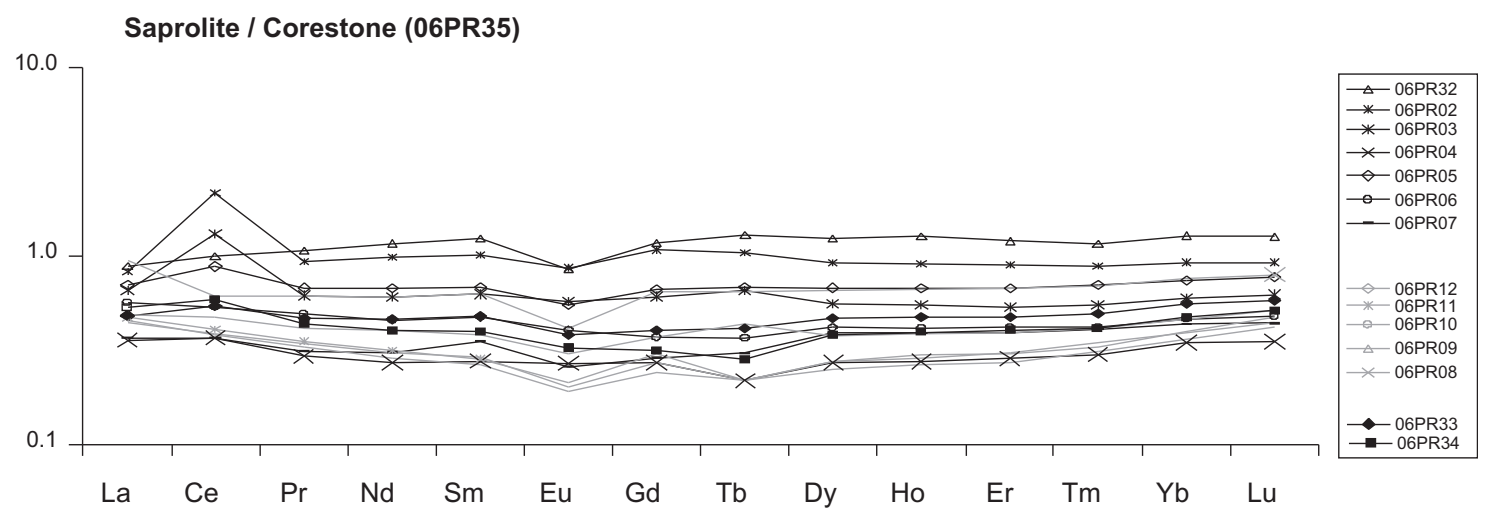

Fig. 4. Rare Earth Element (REE) patterns normalized to the bedrock (corestone 06PR35) for saprolite samples. 
gioclase content $>5 \%$ (detection limit of the XRD technique used) while in the lower saprolite (and at the LG1 site; White et al., 1998), the plagioclase content is below detection limit.

\subsection{The evolution of the chemical composition in the different lithological units}

Major element concentrations of the corestone samples (Table 1) are in the range of those previously determined for the quartz dioritic bedrock of the Rio Icacos Basin (Seiders, 1971; White et al., 1998; Turner et al., 2003).

Above the rindlet-saprolite contact (at $210 \mathrm{~cm}$ depth) the $\mathrm{MgO}, \mathrm{CaO}, \mathrm{Na}_{2} \mathrm{O}, \mathrm{K}_{2} \mathrm{O}$ concentrations strongly decrease, whereas $\mathrm{TiO}_{2}, \mathrm{Fe}_{2} \mathrm{O}_{3}$ and $\mathrm{Al}_{2} \mathrm{O}_{3}$ concentrations increase, relative to the samples below (Fig. 3 and Table 1). Such variations, as previously observed in Puerto Rico profiles, can be linked to weathering processes. However, within the saprolite, above the interface between lower and upper saprolite (at $\approx 120 \mathrm{~cm}$ depth), the $\mathrm{Al}_{2} \mathrm{O}_{3}$ concentrations significantly decrease from about 22 to $<15 \mathrm{wt} . \%$; also $\mathrm{MgO}$ decreases again to lower concentrations. Similarly $\mathrm{TiO}_{2}$ contents decrease from $0.7 \%$ to $<0.6$ wt. $\%$ and $\mathrm{Fe}_{2} \mathrm{O}_{3}$ con- tents decrease from 12 to $<9 \mathrm{wt} . \%$. The abrupt shift in composition between the upper and lower saprolite is also consistent with the hypothesis that the upper saprolite could represent a landslide deposit.

The REE concentrations of the saprolite samples normalized to the corestone also confirm significant differences between lower and upper saprolite zones (Fig. 4). Saprolites close to the rindlet contact $(06 \mathrm{PR} 02,03,32)$ are less depleted in REE relative to the corestone, compared to higher saprolite samples. Samples 06PR02 and 03 also show negative Eu anomalies and significant positive $\mathrm{Ce}$ anomalies $(\mathrm{Ce} /$ $\left.\mathrm{Ce}^{*}=2\right)$. With decreasing depth, all REE concentrations decrease below those of the corestone. In contrast, the REE concentrations of the upper saprolite are always lower than those of the corestone and the $\mathrm{Eu}$ and $\mathrm{Ce}$ anomalies have nearly disappeared.

\subsection{The evolution of the $\mathrm{Sr}$ and $\mathrm{Nd}$ isotopic compositions in the different lithological units}

The $\mathrm{Sr}$ isotopic compositions of the corestone are low and range between 0.70397 and 0.70440 (Table 2). These values are similar to quartz diorite values reported by
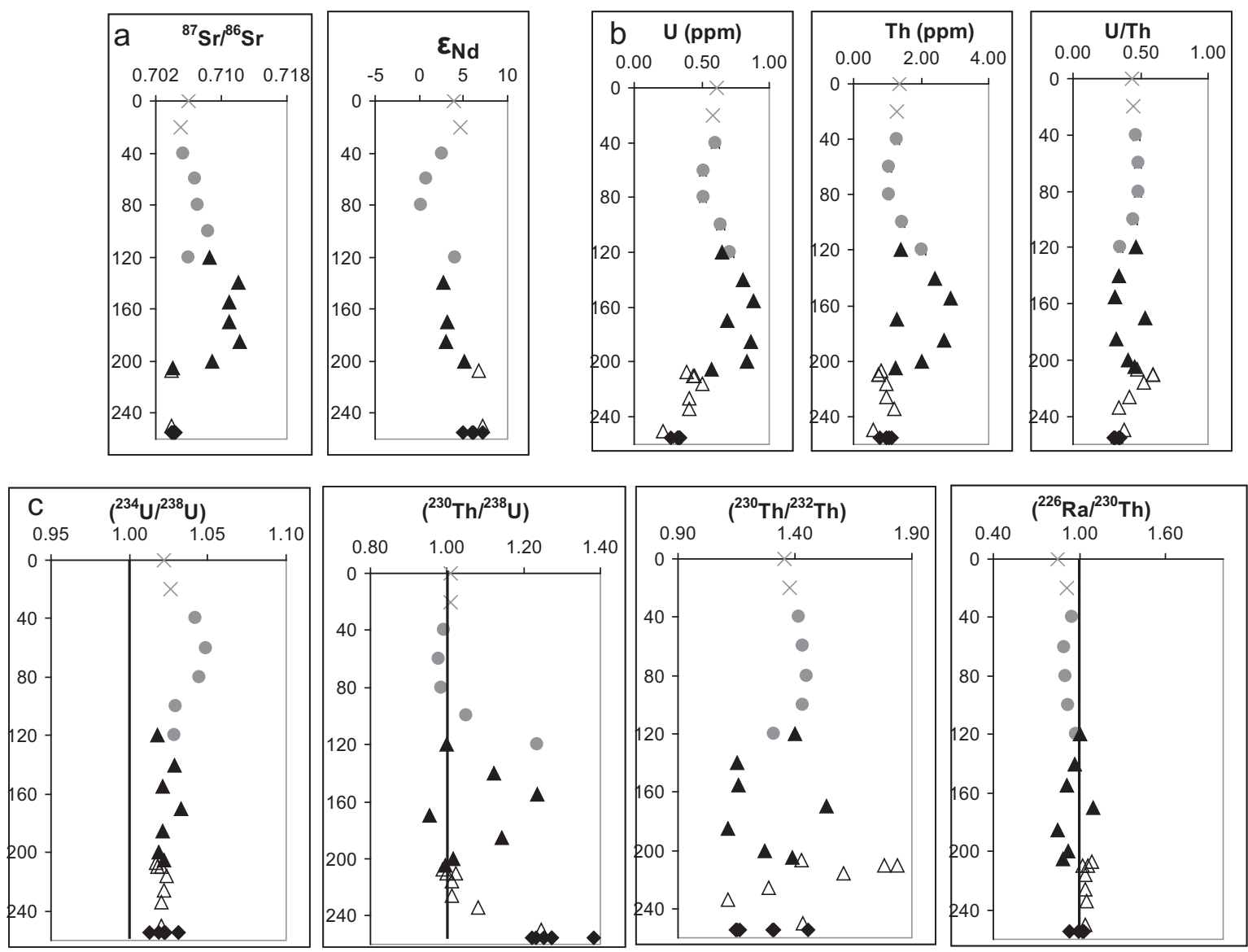

Fig. 5. (a) Depth variations of ${ }^{87} \mathrm{Sr} /{ }^{86} \mathrm{Sr}$ isotope ratios and of $\varepsilon_{\mathrm{Nd}}$ within the studied profile. (b) Depth variations of U and Th concentrations (in ppm) and of $\mathrm{U} / \mathrm{Th}$ concentration ratio. (c) Depth variations of the $\left({ }^{238} \mathrm{U} /{ }^{234} \mathrm{U}\right),\left({ }^{230} \mathrm{Th} /{ }^{238} \mathrm{U}\right),\left({ }^{230} \mathrm{Th} /{ }^{232} \mathrm{Th}\right)$ and $\left({ }^{230} \mathrm{Th} /{ }^{226} \mathrm{Ra}\right)$ activity ratios. The straight line passing through 1 in all these diagrams gives the secular equilibrium value. Error bars are within the symbol size. Same symbols as Fig. 3. 
Pett-Ridge et al. (2009a) and Jones and Kesler (1980). They are also similar to the ${ }^{87} \mathrm{Sr} /{ }^{86} \mathrm{Sr}$ ratio $(0.70411)$ reported for the adjacent volcanoclastic rocks (Frost et al., 1998). The slightly higher isotopic ratios of some corestone samples (up to 0.7044) might be indication of beginning, but still weak, alteration. The rindlet $\mathrm{Sr}$ isotopic compositions vary between 0.70391 and 0.70393 . Their similarity to the corestone isotopic compositions points again to their close magmatic relationship. At the interface between rindlet and lower saprolite (at $205 \mathrm{~cm}$ depth) the ${ }^{87} \mathrm{Sr} /{ }^{86} \mathrm{Sr}$ ratios increase to 0.71227 and then decrease at $120 \mathrm{~cm}$ depth at the transition zone between lower and upper saprolite (Fig. 5). In the upper saprolite a further decrease of the $\mathrm{Sr}$ isotopic composition with decreasing depth is observed and continues into the overlying $20 \mathrm{~cm}$ thick soil (Fig. 5). The trends in $\mathrm{Sr}$ isotopes in the two saprolite zones is consistent with the landslide hypothesis. The high ${ }^{87} \mathrm{Sr} /{ }^{86} \mathrm{Sr}$ ratio at the top of the lower saprolite $(0.71215)$ is in between ratios reported by Pett-Ridge et al. (2009a) for the surface soil from the undisturbed LG-1 ridge top (0.71080) and for local atmospheric input (0.71343). The trend in ${ }^{87} \mathrm{Sr} /{ }^{86} \mathrm{Sr}$ between this high value at the upper-lower saprolite interface and the low value of the corestone describes a mixing line similar to that observed by Pett-Ridge et al. (2009a). Subsequent burial of the lower saprolite by a landslide bearing less-weathered saprolite would result in an upper saprolite zone that has a lower ${ }^{87} \mathrm{Sr} /{ }^{86} \mathrm{Sr}$ ratio, as observed.

The $\varepsilon_{\mathrm{Nd}}$ value of the corestone is +6.7 , which is identical (within error of the measurement) with the previously published bedrock $\varepsilon_{\mathrm{Nd}}$ value of +7 (Pett-Ridge et al., 2009a). As for $\mathrm{Sr}$ isotopic ratios, the $\mathrm{Nd}$ isotopic compositions of the rindlets are similar to those of the corestone. The $\varepsilon_{\mathrm{Nd}}$ values of the saprolite samples decrease with decreasing depth from +5.2 at $200 \mathrm{~cm}$ depth to $\approx 0$ at $80 \mathrm{~cm}$ depth. Then the $\varepsilon_{\mathrm{Nd}}$ increases again and reaches an $\varepsilon_{\mathrm{Nd}}$ value of +5 close to the surface (Fig. 5).

\subsection{The $\mathrm{U}-\mathrm{Th}-\mathrm{Ra}$ disequilibria}

The $\left({ }^{234} \mathrm{U} /{ }^{238} \mathrm{U}\right)$ ratios slightly increase from the corestone to the top of the saprolite (Fig. 5). However, U-Th concentrations and ${ }^{238} \mathrm{U}-{ }^{234} \mathrm{U}-{ }^{230} \mathrm{Th}-{ }^{226} \mathrm{Ra}$ isotopes do not show simple trends along the weathering profile from the corestone to the top of the soil. The trends are detailed below.

\subsubsection{Corestone}

The systematic occurrence of radioactive disequilibria among the U-series nuclides within the five corestone samples indicates that all of them have already been weathered to some extent. Indeed, an unweathered bedrock older than $1 \mathrm{Myr}$ must be in secular equilibrium (i.e. $\left({ }^{234} \mathrm{U} /{ }^{238} \mathrm{U}\right)=$ $\left.\left(230 \mathrm{Th} /{ }^{238} \mathrm{U}\right)=\left({ }^{226} \mathrm{Ra} /{ }^{230} \mathrm{Th}\right)=1\right)$. The $\left({ }^{234} \mathrm{U} /{ }^{238} \mathrm{U}\right)$ and $\left({ }^{230} \mathrm{Th} /{ }^{238} \mathrm{U}\right)$ values of the corestone samples are all significantly $>1$ (Fig. 5). This observation is consistent with the presence of traces of kaolinite in some of the corestones. It is also consistent with the fact that all samples analyzed for this study are located at the periphery of the corestone (Fig. 2) which has been shown to be affected by incipient weathering including biotite oxidation (Buss et al., 2008). The $\left({ }^{230} \mathrm{Th} /{ }^{238} \mathrm{U}\right)$ activity ratios of the corestone samples are all $>1(1.23-1.38)$ and suggest that this incipient weathering is marked either by $U$ leaching or Th gain (Fig. 5). However, all corestone samples are also characterized by $\left({ }^{234} U /{ }^{238} U\right)>1$, which cannot be explained by simple $U$ loss (Fig. 5). If Th is assumed to be immobile during incipient weathering, then it is possible that ${ }^{234} U$ uptake occurs concurrently to ${ }^{238} \mathrm{U}$ loss. Therefore, even during the early stages of weathering, the mobility of the different radioactive nuclides must be described in term of enrichment and depletion. The position of the samples around the corestone does not allow the use of these data for calculating the propagation rate of this incipient weathering front within the corestone: a radial transect across the corestone would be required.

\subsubsection{Rindlets and saprolite}

Compared to the corestone samples, most of the 2003 2004 rindlets have very similar Th but higher U concentrations ( $\sim 0.4 \mathrm{ppm})$ (Table 2$)$. This might point to $U$ enrichment during rindlet formation without significant $\mathrm{Th}$ mobility. The observation of a $\left({ }^{234} \mathrm{U} /{ }^{238} \mathrm{U}\right)$ activity ratio $>1$ in these rindlets is consistent with this hypothesis. From the corestone to the outer rindlets, the $\left({ }^{230} \mathrm{Th} /{ }^{232} \mathrm{Th}\right)$ activity ratio increases and the $\left({ }^{230} \mathrm{Th} /{ }^{238} \mathrm{U}\right)$ activity ratio decreases while $\left({ }^{226} \mathrm{Ra} /{ }^{230} \mathrm{Th}\right)$ activity ratios are constant but slightly $>1$ (Fig. 5). As observed above, the variations of $\mathrm{U}$ and $\mathrm{Th}$ concentrations or U-series disequilibria are very different between the upper and lower saprolites. This is well illustrated by the U/Th, the $\left({ }^{230} \mathrm{Th} /{ }^{232} \mathrm{Th}\right)$ or $\left({ }^{234} \mathrm{U} /{ }^{238} \mathrm{U}\right)$ ratios which are smaller in the lower saprolite than in the upper saprolite (Fig. 5).

\section{DISCUSSION}

\subsection{Variations of the major and trace element concentrations in bedrock and rindlets}

The similarity between the REE patterns of the corestone samples and the rindlet samples (not shown) along with their close $\mathrm{Sr}-\mathrm{Nd}$ isotopic ratios point to the common magmatic origin of all of these samples. The petrological and geochemical data suggest, however, as already noticed in previous studies on the Rio Blanco stock (Turner et al., 2003; Buss et al., 2008), that the corestone-rindlet system is not mineralogically homogeneous at the centimeter or decimetre scale. Thus, for the discussion of the mobility of chemical elements during the weathering of the quartz diorite bedrock and the formation of rindlets and saprolite, an average chemical composition of the fresh bedrock has been used as reference. This allows identification of the mineralogical sequence of quartz diorite weathering within the rindlet zones (Turner et al., 2003; Buss et al., 2008). The bedrock was first affected by biotite oxidation which began in the corestone and results in a loss of $\mathrm{K}$ across the rindlet zone; it is followed by plagioclase weathering across the rindlet zone causing $\mathrm{Na}$ and $\mathrm{Ca}$ loss; finally hornblende alters first by oxidation and then by rapid and complete 
weathering within the outermost rindlets to form material that was termed "protosaprolite" in an earlier publication (Buss et al., 2008). The six 2003-2004 rindlets analyzed here belong to this trend of weathering. They constitute a relatively simple weathering system, which is progressively modified from the base to the top of the rindlet zone by increasing biotite oxidation and plagioclase transformation: such a weathering system is a priori well suited for determining the propagation rate of the weathering front with help of U-series systematics.

\subsection{Variations of the major and trace element concentrations in the saprolite}

As already proposed for major and trace element variations in the LG-1 profile (White et al., 1998), and confirmed by the mineralogical data obtained in this study and by Buss et al. (2008), the significant loss of mobile elements in the "outcrop" profile at the corestone/saprolite transition is mainly due to the weathering of primary minerals including plagioclase, biotite and hornblende and precipitation of secondary minerals, primarily kaolinite and goethite. Such mineralogical transformations may explain the REE distribution patterns of the lower saprolite at the contact with the rindlets. REE distribution patterns are indeed still similar to those of the rindlets but with significant positive $\mathrm{Ce}$ anomalies. This is consistent with precipitation of insoluble $\mathrm{CeO}_{2}$ due to oxidation of $\mathrm{Ce}^{3+}$ to $\mathrm{Ce}^{4+}$. This is accompanied by accumulations of oxides/hydroxides of $\mathrm{Al}$ and $\mathrm{Fe}$ probably due to dissolution of biotite as indicated by the comparatively high $\mathrm{Fe}_{2} \mathrm{O}_{3}$ and $\mathrm{Al}_{2} \mathrm{O}_{3}$ contents in the lower saprolite (Table 1).

As noted in the Section 4, the upper saprolite layer (between $40-120 \mathrm{~cm}$ depth) is more enriched in primary minerals than the basal saprolite (between 120-205 cm depth), with plagioclase and hornblende contents $>5 \%$ in the upper saprolite and not detectable in the lower one. This might indicate that that the lower saprolite is more weathered than the upper. Such a conclusion is entirely consistent with the depth variation along the profile of loss-on-ignition (LOI) and of the chemical weathering index $\left(\mathrm{CWI}=\left[\left(\mathrm{Al}_{2}\right.\right.\right.$ $\left.\mathrm{O}_{3}+\mathrm{Fe}_{2} \mathrm{O}+\mathrm{TiO}_{2}+\mathrm{LOI}\right) /$ sum of major oxides $\left.] \times 100\right)$ (Sueoka, 1988), both of which can be considered as proxies for the degree of weathering. LOI is indeed lower in the upper part than in the lower part of the saprolite (Fig. 3). The CWI, which ranges classically between 13 and $15 \%$ in unweathered granitic bedrocks and increases with weathering intensity (Taylor and Eggleton, 2001), is lower in the upper than in the lower saprolite (Fig. 3). These observations indicate that the upper part of the saprolite is less weathered than the lower one. If the upper saprolite represents landslide debris, it was either transported from a less weathered zone and/or included broken rindlets that have since disappeared. Therefore only the samples from the lower saprolite, close to rindlets and corestone and, consequently, close to the weathering front, shall be used for the determination of the weathering rates by $\mathrm{U}-\mathrm{Th}-\mathrm{Ra}$ disequilibria (measured in a series of samples collected along a vertical depth profile).

\subsection{Variations of $\mathrm{Sr}$ and $\mathrm{Nd}$ isotopes ratios in saprolite}

$\mathrm{Sr}$ and $\mathrm{Nd}$ isotope data and mass balance estimations for the neighboring LG-1 soil/saprolite profile are consistent with significant deposition of atmospheric dust at that site (Pett-Ridge et al., 2009a,b). This is also in agreement with McDowell et al. (1990) who noted a Saharan dust component in precipitation in the Luquillo Experimental Forest. Similarly, the $\mathrm{Sr}-\mathrm{Nd}$ budget in the saprolite is consistent with weathering of primary minerals affected by atmospheric dust deposition. For example, this is emphasized by the scattered data in the $\varepsilon_{\mathrm{Nd}}-{ }^{87} \mathrm{Sr} /{ }^{86} \mathrm{Sr}$ diagram below the $\varepsilon_{\mathrm{Nd}}$ values of primary bedrock minerals (Fig. 6). A similar observation has been made for the $\mathrm{Sr}-\mathrm{Nd}$ isotope data in granite-derived soils in the Vosges Mountains (France; Aubert et al., 2001; Stille et al., 2006). The saprolite $\mathrm{Sr}$ and $\mathrm{Nd}$ isotope data can only be explained by an additional external atmospheric source with a low continental crust-like $\varepsilon_{\mathrm{Nd}}$ value such as Saharan dust (Pett-Ridge et al., 2009a,b). Specifically, the position of the saprolite data points to the right of the theoretical mixing hyperbolae between the fresh quartz diorite end-member and the atmospheric dust end-member (Fig. 6), is entirely consistent with deposition of atmospheric dust to soil and saprolite. The observation that the samples from the lower and upper saprolite plot along two different trends in the $\varepsilon_{\mathrm{Nd}}{ }^{87} \mathrm{Sr} /{ }^{86} \mathrm{Sr}$ diagram reinforces the interpretation of the occurrence of two different units within the saprolite. The two mixing trends also support the suggestion that the upper unit is less

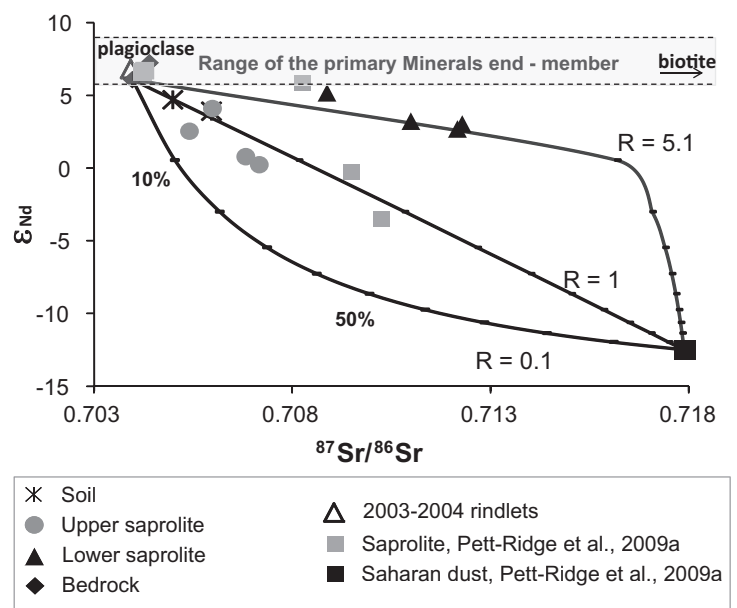

Fig. 6. Plot of $\varepsilon_{\mathrm{Nd}}$ versus ${ }^{87} \mathrm{Sr} /{ }^{86} \mathrm{Sr}$ ratios for samples of the outcrop profile. (Data sources: this study; Pett-Ridge et al., 2009a,b). The mixing curves are calculated between quartz diorite corestone and Saharan dust by changing $[\mathrm{Sr}]$ in the corestone in order to fit all the regolith data. $(R=([\mathrm{Sr}] /[[\mathrm{Nd}])$ corestone $/([\mathrm{Sr}] /$ $[\mid \mathrm{Nd}])$ Saharan dust $-R=5.1$ for the actual $\mathrm{Sr}$ concentration in the corestone (259 ppm), $R=1$ for a $\mathrm{Sr}$ concentration of $50 \mathrm{ppm}$ and $R=0.1$ for a $\mathrm{Sr}$ concentration of $3 \mathrm{ppm}$. Range of primary minerals is defined by the plagioclases and the biotites data, which have respectively the lowest $\left({ }^{87} \mathrm{Sr} /{ }^{86} \mathrm{Sr} \sim 0.704\right)$ and the highest $\left({ }^{87} \mathrm{Sr} /{ }^{86} \mathrm{Sr} \sim 0.72527\right)$ ratios among the primary minerals of the quartz diorite (Pett-Ridge et al., 2009a,b). 
weathered than the lower one; indeed, the lower unit trend, in the $\varepsilon_{\mathrm{Nd}^{-}}{ }^{87} \mathrm{Sr} /{ }^{86} \mathrm{Sr}$ diagram, can be explained by a larger loss of mobile elements and/or lower amount of non-radiogenic minerals, such as hornblende and plagioclase. Based on the position of the data points in Fig. 6, one might also suggest that the outcrop profile is less affected by atmospheric deposition than the LG-1 profile studied by PettRidge et al. (2009a). The fact that the nature and/or intensity of atmospheric depositions depends on relief and altitude of the site (e.g., Doucet and Carignan, 2001; Pourcelot et al., 2003) might explain why one observes at the location of the LG1 site on a ridge top at $680 \mathrm{~m}$ elevation more atmospheric dust than in the outcrop profile at lower elevation $(<600 \mathrm{~m})$. Alternatively, if the upper saprolite is composed of landslide debris, it likely has been exposed to atmospheric inputs for less time than saprolite/ soil units formed in situ in the watershed.

It is, however, difficult to precisely estimate the dust contribution from the mixing curve in the $\varepsilon_{\mathrm{Nd}^{-}}{ }^{87} \mathrm{Sr} /{ }^{86} \mathrm{Sr}$ diagram because the dust particles did not mix with material of the fresh quartz diorite but with Sr-depleted soil and saprolite. In addition, the saprolite-dust system underwent further weathering which has offset the isotopic compositions from a pure mixing curve (Pett-Ridge et al., 2009a). The important point to note here is that the $\varepsilon_{\mathrm{Nd}}$ and ${ }^{87} \mathrm{Sr} /{ }^{86} \mathrm{Sr}$ data confirm that dust accretion is an important parameter that needs to be taken into account in order to establish a correct weathering mass balance calculation at the scale of a watershed as well as at the scale of a weathering profile; This has been also shown for Hawaiian soils (Pett-Ridge et al., 2007) and soils at Cameroun (Dia et al., 2006; Pelt et al., 2011).

Dust deposition probably also influences the $\mathrm{U}$ and $\mathrm{Th}$ budget of the studied profile. However, its contribution is difficult to estimate because $\mathrm{U}$ and $\mathrm{Th}$ concentrations of the Aeolian dusts have to be known. To the best of our knowledge, no direct measurements are available for the Puerto Rico site. Nevertheless, the wind-borne Saharan dust collected at Barbados (Rydell and Prospero, 1972) indicates that $\mathrm{U}$ and $\mathrm{Th}$ concentrations in Aeolian particles can be high, with $\mathrm{U}$ and $\mathrm{Th}$ concentrations of 3.6 and $12.4 \mathrm{ppm}$, respectively. Such concentrations are consistent with upper continental crust values (2.8 and $10.7 \mathrm{ppm}$, respectively, Taylor and McLennan, 1995). These concentrations are high compared to the $\mathrm{U}$ and $\mathrm{Th}$ concentrations in the upper and lower saprolite (U: 0.6-0.9 ppm; Th: $1.2-$ $2.4 \mathrm{ppm})$; such values would imply that a deposition of about $5 \%$ of atmospheric dust would for instance control about $10-15 \%$ of $U$ and $T h$ in the weathering profile. This rough estimation indicates that, in contrast to $\mathrm{U}$ and $\mathrm{Th}$ rainwater contributions (Riotte and Chabaux, 1999; Chabaux et al., 2003a), the $U$ and Th dust contributions are not negligible. For the Puerto Rico case, the Aeolian contribution probably explains the $\left({ }^{234} \mathrm{U} /{ }^{238} \mathrm{U}\right)$ ratios $>1$ along the weathering profile with highest values in the upper part of the saprolite, since wind-borne Saharan dust is marked by ${ }^{234} \mathrm{U}$ enrichments with a $\left({ }^{234} \mathrm{U} /{ }^{238} \mathrm{U}\right)$ of up to 1.08 ( $\mathrm{Ry}-$ dell and Prospero, 1972). Nonetheless, dispersion of the data points in the $\left({ }^{234} \mathrm{U} /{ }^{238} \mathrm{U}\right)$ vs. ${ }^{87} \mathrm{Sr} /{ }^{86} \mathrm{Sr}$ or $\left({ }^{230} \mathrm{Th} /{ }^{232} \mathrm{Th}\right)$ vs. $\varepsilon_{\mathrm{Nd}}$ diagrams (not shown) clearly suggests that the U-Th budget of the saprolite is not only controlled by dust accretion but also by geochemical fractionations associated with water-rock interaction in the weathering profile. The model used in this study for interpreting the U-series data integrate all the input and redistribution fluxes that affect the profile; it does not require any distinction between the flux controlled by Aeolian inputs and those controlled by weathering processes.

\subsection{Variations of $U$-series nuclides and determination of weathering rates}

The studied profile is a spheroidal weathering system, which does not necessarily evolve along the vertical direction. Therefore, the approach proposed in Section 3.1 for determining weathering rates from a series of samples collected along a vertical depth profile can be applied only to the samples collected within the rindlet zone and within the lower saprolite. In the following, the determination of the regolith production rate is presented for these two zones.

\subsubsection{Determination of production rate in the lower saprolite}

The complete transformation from rindlet to saprolite is reached in sample 06PR02. The sample just below has intermediate geochemical characteristics between those of bedrock and saprock. For the calculation of the weathering rate, it is therefore appropriate to use samples 06PR02 to 06PR06. Sample 06PR04 has not been used as it is marked by atypical geochemical characteristics including a lower degree of weathering (lower LOI and CWI) and lower Th and REE concentrations than observed for the 4 other lower saprolite samples. The origin of these characteristics is not fully understood but is possibly due to mineralogical heterogeneities in the parent bedrock. For the four remaining lower saprolite samples, several solving configurations can be envisaged (see Section 3.1). The first one is to consider the variation of the ${ }^{238} \mathrm{U}-{ }^{234} \mathrm{U}-{ }^{230} \mathrm{Th}-{ }^{226} \mathrm{Ra}$ disequilibrium across the lower saprolite. This allows for the determination of an average weathering rate if one assumes that the weathering is isovolumetric with a constant propagation rate over the time. The second configuration introduces the ${ }^{232} \mathrm{Th}$ in addition to the four other nuclides. This should theoretically allow for the calculation of the mean age of each sample as well as the average production rate. The data of the 4 lower saprolite samples were, therefore, modeled in three different ways: one by using only ${ }^{238} \mathrm{U}-{ }^{234} \mathrm{U}-{ }^{230} \mathrm{Th}-{ }^{226} \mathrm{Ra}$ nuclides and assuming a constant regolith production rate $P$; the two other ones by using ${ }^{232} \mathrm{Th}$, once by assuming $P$ to be constant over the lower saprolite profile and once by calculating the age of each sample. Therefore, in the latter approach the constancy of the regolith production rate $\mathrm{P}$ is not a necessary assumption.

The results of the three simulations are given in Table 3. They indicate that the simulations using only ${ }^{238}{ }^{2}-{ }^{234} \mathrm{U}-{ }^{230} \mathrm{Th}-{ }^{226} \mathrm{Ra}$ data without ${ }^{232} \mathrm{Th}$ fit the data better than the two simulations using ${ }^{232} \mathrm{Th}$. Furthermore, the mean weathering rates are different depending on whether ${ }^{232} \mathrm{Th}$ is used or not. Without fitting the ${ }^{232} \mathrm{Th}$ data, the 
Table 3

Weathering propagation rate, and mobility parameters $\left(k_{i}, f_{i}\right)$ derived for the models for the lower saprolite. The model is solved multiple times to obtain about 1000 sets of solutions for each simulation, as described in Appendix A1. The $\left(P, k_{i}, f_{i}\right)$ parameters are taken as the average of the sets of solution values, and the uncertainties are calculated as the standard deviation on the sets of values.

\begin{tabular}{|c|c|c|c|c|c|c|c|c|c|c|c|c|c|c|c|c|c|c|c|c|c|c|c|c|}
\hline & $\begin{array}{l}P(\mathrm{~m} / \\
\mathrm{Ma})\end{array}$ & $\begin{array}{l}k 8 \\
\left(10^{-6}\right.\end{array}$ & $\begin{array}{c}k 4 \\
\left.\mathrm{yr}^{-1}\right)\end{array}$ & $k 0$ & $k 6$ & $k 2$ & $\begin{array}{l}f 8 \\
\left(10^{-6}\right.\end{array}$ & $\begin{array}{c}f 4 \\
\left.\mathrm{yr}^{-1}\right)\end{array}$ & $f 0$ & $f 6$ & $f 2$ & $\begin{array}{l}k 4 / \\
k 8\end{array}$ & $\begin{array}{l}k 0 / \\
k 8\end{array}$ & $\begin{array}{l}k 6 / \\
k 8\end{array}$ & $\begin{array}{l}k 2 / \\
k 8\end{array}$ & $\begin{array}{l}f 4 / \\
f 8\end{array}$ & $\begin{array}{l}f 0 / \\
f 8\end{array}$ & $\begin{array}{l}f 6 / \\
f 8\end{array}$ & $\begin{array}{l}f 2 / \\
f 8\end{array}$ & $\begin{array}{l}k 8 / \\
f 8\end{array}$ & $\begin{array}{l}k 4 / \\
f 4\end{array}$ & $\begin{array}{l}k 0 / \\
f 0\end{array}$ & $\begin{array}{l}k 6 / \\
f 6\end{array}$ & $\begin{array}{l}k 2 / \\
f 2\end{array}$ \\
\hline \multicolumn{25}{|c|}{$P$ constant without ${ }^{232} \mathrm{Th}$} \\
\hline Mean & 45 & 678 & 678 & 642 & 729 & & 1.00 & 1.01 & 1.00 & 1.22 & & 1.00 & 0.95 & 1.08 & & 1.01 & 1.00 & 1.22 & & 675 & 669 & 641 & 596 & \\
\hline \pm & 2 & 81 & 81 & 79 & 80 & & 0.34 & 0.34 & 0.33 & 0.42 & & 0.17 & 0.16 & 0.17 & & 0.48 & 0.47 & 0.59 & & 243 & 241 & 223 & 217 & \\
\hline Mean & 10 & 129 & 129 & 120 & 198 & & 0.52 & 0.52 & 0.45 & 1.01 & & 1.00 & 0.93 & 1.54 & & 1.01 & 0.88 & 1.97 & & 249 & 246 & 266 & 195 & \\
\hline \pm & 2 & 42 & 42 & 42 & 41 & & 0.38 & 0.39 & 0.32 & 0.83 & & 0.46 & 0.45 & 0.60 & & 1.06 & 0.90 & 2.18 & & 202 & 200 & 207 & 165 & \\
\hline $\begin{array}{l}\text { Mean (1100 } \\
\text { runs) }\end{array}$ & 44 & 697 & 697 & 663 & 749 & & 0.84 & 0.85 & 0.84 & 1.06 & & 1.00 & 0.95 & 1.07 & & 1.01 & 0.99 & 1.26 & & 829 & 822 & 794 & 709 & \\
\hline \pm & 12 & 270 & 270 & 261 & 264 & & 0.44 & 0.44 & 0.43 & 0.56 & & 0.55 & 0.53 & 0.56 & & 0.75 & 0.73 & 0.94 & & 539 & 534 & 513 & 454 & \\
\hline \multicolumn{25}{|c|}{$P$ constant with ${ }^{232} \mathrm{Th}$} \\
\hline Mean & 119 & 1543 & 1540 & 1429 & 1578 & 1339 & 26 & 26 & 26 & 31 & 25 & 1.00 & 0.93 & 1.02 & 0.87 & 1.00 & 1.01 & 1.19 & 0.97 & 59 & 59 & 54 & 51 & 53 \\
\hline \pm & 19 & 215 & 215 & 208 & 204 & 205 & 22 & 22 & 22 & 27 & 19 & 0.20 & 0.19 & 0.19 & 0.18 & 1.22 & 1.20 & 1.46 & 1.12 & 51 & 51 & 45 & 45 & 41 \\
\hline \multicolumn{25}{|c|}{$P$ variable with ${ }^{232} T h$} \\
\hline P1 (06PR03) & 46 & & & & & & & & & & & & & & & & & & & & & & & \\
\hline \pm & 3 & & & & & & & & & & & & & & & & & & & & & & & \\
\hline P2 (06PR05) & 74 & & & & & & & & & & & & & & & & & & & & & & & \\
\hline \pm & 4 & & & & & & & & & & & & & & & & & & & & & & & \\
\hline P3 (06PR06) & 17 & 1262 & 1262 & 1218 & 1313 & 1186 & 1.21 & 1.21 & 1.32 & 1.47 & 1.38 & 1.00 & 0.97 & 1.04 & 0.94 & 1.01 & 1.09 & 1.22 & 1.15 & 1046 & 1038 & 925 & 895 & 857 \\
\hline \pm & 11 & 101 & 101 & 99 & 100 & 97 & 0.11 & 0.11 & 0.12 & 0.14 & 0.13 & 0.11 & 0.11 & 0.12 & 0.11 & 0.13 & 0.14 & 0.16 & 0.15 & 129 & 128 & 114 & 110 & 106 \\
\hline
\end{tabular}




\section{Lower saprolite P constant without ${ }^{232} \mathrm{Th}$}

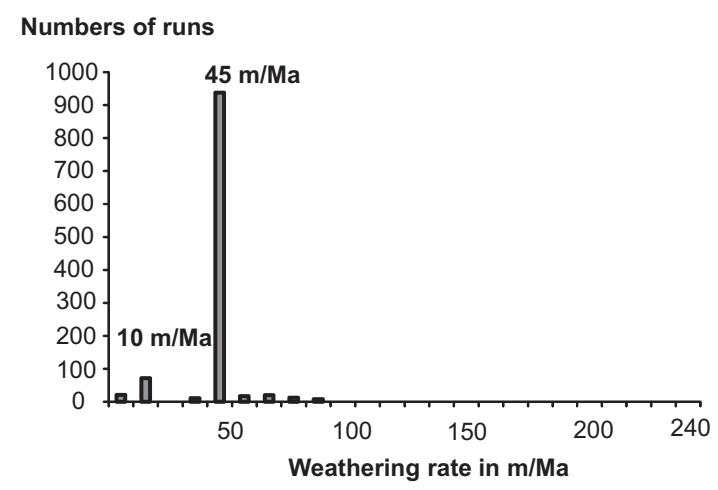

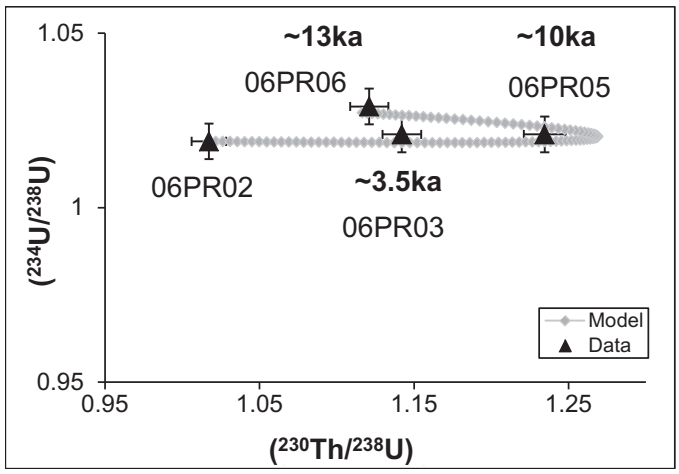

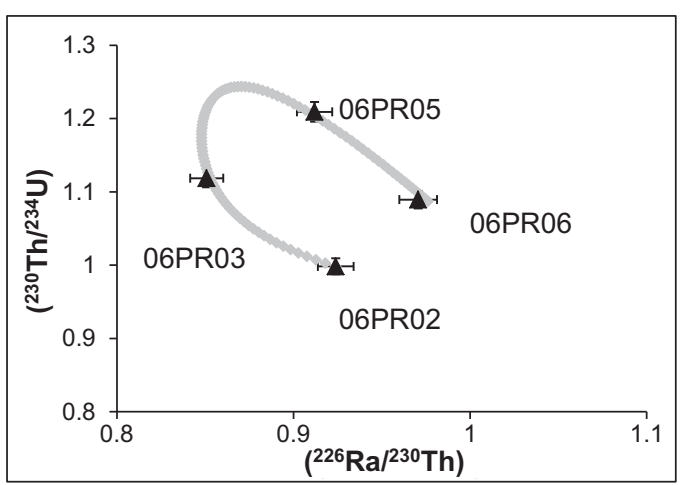

Fig. 7. Measured $\left({ }^{234} \mathrm{U} /{ }^{238} \mathrm{U}\right)$ and $\left({ }^{230} \mathrm{Th} /{ }^{238} \mathrm{U}\right)$ activity ratios and $\left({ }^{230} \mathrm{Th} /{ }^{234} \mathrm{U}\right)$ and $\left({ }^{226} \mathrm{Ra} /{ }^{230} \mathrm{Th}\right)$ activity ratios for the lower saprolite. Dashed line indicates theoretical time evolution of activity ratios of the 06PR02 sample for saprolite with parameters from Table 3 using the model described in the text (assuming a constant weathering rate). Ages reported on the graph are the ages of the different samples relative to the sample 06PR02, taken as the initial condition. The histogram gives the occurrence of the different production rates obtained from about 1000 retained runs of the simulation.

average propagation rate is relatively low $(\sim 45 \pm 12 \mathrm{~m} /$ Ma). However, the simulation results can statistically be subdivided into two populations: the largest number of simulations is consistent with $45 \pm 2 \mathrm{~m} / \mathrm{Ma}$ while fewer simulations yield $10 \pm 2 \mathrm{~m} / \mathrm{Ma}$ (Fig. 7). These two populations strongly depend on the values of U-Th-Ra mobility parameters used for calculation. In the first case, the leaching parameters of the $\mathrm{U}-\mathrm{Th}-\mathrm{Ra}$ nuclides have relatively similar values. On the other hand, for low regolith production rates, the Ra leaching coefficient has to be significantly higher than that of $\mathrm{U}$ or Th. ${ }^{226} \mathrm{Ra},{ }^{230} \mathrm{Th}$ and ${ }^{234} \mathrm{U}$ nuclides derive from ${ }^{238} \mathrm{U}$ by radioactive decay and, therefore, may occupy the same crystallographic sites in minerals; likewise their rates of release by leaching and/or dissolution of minerals should be similar. Under these conditions a weathering rate of $45 \pm 2 \mathrm{~m} / \mathrm{Ma}$ can be derived for the formation of the lower saprolite.

\subsubsection{Determination of production rate in the 2003-2004 rindlets}

For reasons given in Electronic Annex EA1, only the 2003-2004 rindlets can be used to estimate the weathering rate. More precisely, the five lower 2003-2004 rindlets have been used because they belong to a relatively simple weathering system characterized by the progressive weathering of biotite and plagioclase. The outermost sample, however, is saprock, also called 'protosaprolite' (Buss et al., 2008), and marked by other mineral transformations; it has been excluded from weathering rate estimations. For the five remaining 2003-2004 rindlets, the rate has been determined according to the modeling approaches used for the lower saprolite. Results are given in Table 4. Assuming a constant regolith propagation rate $P$, either with or without ${ }^{232} \mathrm{Th}$, it is calculated similar mean weathering rates but different mobility parameters for Th and $\mathrm{Ra}$. The third approach seeking to determine the age of each sample did not yield satisfactory results. Similar to the saprolite modeling, the ${ }^{238} \mathrm{U}$-series nuclides-based simulation yields two populations of weathering rates at $52 \pm 13 \mathrm{~m} / \mathrm{Ma}$ and at $8 \pm 5 \mathrm{~m} / \mathrm{Ma}$ (Fig. 8). The two populations only depend on the relative $\mathrm{Ra}$, Th and $\mathrm{U}$ leaching rates. As for the lower saprolite, the fact that the ${ }^{234} \mathrm{U}-{ }^{230} \mathrm{Th}-{ }^{226} \mathrm{Ra}$ nuclides belong to the same ${ }^{238} \mathrm{U}$-series $a$ priori implies that the degree of mobilization of these elements during weathering is similar, which in turn allows for the derivation of a mean weathering rate of $52 \pm 13 \mathrm{~m} / \mathrm{Ma}$. The fact that the data fitting works better without ${ }^{232} \mathrm{Th}$ in both the rindlet zone and the saprolite is odd and shall be discussed in more detail in the following section.

\subsection{Geomorphological and geochemical implications}

\subsubsection{Implications for the regolith formation}

The above simulations yield consistent weathering advance rates for rindlets and saprolite. The $U$ input param- 
Table 4

Weathering propagation rate, and mobility parameters $\left(k_{i}, f_{i}\right)$ derived for the models for the 2003-2004 rindlets. The model is solved multiple times to obtain about 1000 sets of solutions for each simulation, as described in Appendix A1. The $\left(P, k_{i}, f_{i}\right)$ parameters are taken as the average of the sets of solution values, and the uncertainties are calculated as the standard deviation on the sets of values.

\begin{tabular}{|c|c|c|c|c|c|c|c|c|c|c|c|c|c|c|c|c|c|c|c|c|c|c|c|}
\hline $\begin{array}{l}P(\mathrm{~m} / \\
\mathrm{Ma})\end{array}$ & $\begin{array}{l}k 8 \\
\left(10^{-}\right.\end{array}$ & $\begin{array}{c}k 4 \\
\mathrm{yr}^{-1}\end{array}$ & $k 0$ & $k 6$ & $k 2$ & $\begin{array}{l}f 8 \\
(10\end{array}$ & $\begin{array}{c}f 4 \\
\mathrm{yr}^{-1}\end{array}$ & $f 0$ & $f 6$ & $f 2$ & $\begin{array}{l}k 4 / \\
k 8\end{array}$ & $\begin{array}{l}k 0 / \\
k 8\end{array}$ & $\begin{array}{l}k 6 / \\
k 8\end{array}$ & $\begin{array}{l}k 2 / \\
k 8\end{array}$ & $\begin{array}{l}f 4 / \\
f 8\end{array}$ & $\begin{array}{l}f 0 / \\
f 8\end{array}$ & $\begin{array}{l}f 6 / \\
f 8\end{array}$ & $\begin{array}{l}f 2 / \\
f 8\end{array}$ & $k 8 / f 8$ & $k 4 / f 4$ & $k 0 / f 0$ & $k 6 / f 6$ & $\begin{array}{l}k 2 / \\
f 2\end{array}$ \\
\hline
\end{tabular}

\begin{tabular}{|c|c|c|c|c|c|c|c|c|c|c|c|c|c|c|c|c|c|c|c|c|c|c|c|c|}
\hline \multicolumn{25}{|c|}{$P$ constant without ${ }^{232} \mathrm{Th}$} \\
\hline Mean & 52 & 1338 & 1339 & 1283 & 1270 & & 1338 & 1339 & 1283 & 1270 & & 1.00 & 0.96 & 0.95 & & 1.00 & 0.69 & 0.70 & & 13.2 & 13.1 & 18.4 & 17.9 & \\
\hline \pm & 13 & 325 & 325 & 340 & 338 & & 325 & 325 & 340 & 338 & & 0.34 & 0.34 & 0.34 & & 1.64 & 0.99 & 1.01 & & 15.4 & 15.5 & 16.9 & 16.6 & \\
\hline Mean & 8 & 1191 & 1246 & 167 & 171 & & 478 & 500 & 52 & 60 & & 1.05 & 0.14 & 0.14 & & 1.05 & 0.11 & 0.13 & & 2.49 & 2.49 & 3.21 & 2.84 & \\
\hline \pm & 5 & 517 & 345 & 112 & 111 & & 214 & 146 & 33 & 34 & & 0.54 & 0.11 & 0.11 & & 0.56 & 0.09 & 0.09 & & 1.55 & 1.00 & 2.98 & 2.44 & \\
\hline $\begin{array}{l}\text { Mean (672 } \\
\text { runs) }\end{array}$ & 32 & 1272 & 1298 & 786 & 781 & & 269 & 279 & 62 & 66 & & 1.02 & 0.62 & 0.61 & & 1.04 & 0.23 & 0.25 & & 4.73 & 4.65 & 12.7 & 11.8 & \\
\hline \multicolumn{25}{|c|}{$P$ constant with ${ }^{232} T h$} \\
\hline Mean & 25 & 1861 & 1730 & 444 & 459 & 110 & 1005 & 935 & 193 & 210 & 23 & 0.93 & 0.24 & 0.25 & 0.06 & 0.93 & 0.19 & 0.21 & 0.02 & 1.85 & 1.85 & 2.30 & 2.19 & 4.80 \\
\hline \pm & 11 & 243 & 233 & 194 & 206 & 50 & 132 & 126 & 82 & 90 & 10 & 0.17 & 0.11 & 0.12 & 0.03 & 0.18 & 0.09 & 0.09 & 0.01 & 0.34 & 0.35 & 1.41 & 1.36 & 3.10 \\
\hline
\end{tabular}

$P$ variable with ${ }^{232} \mathrm{Th}$

P1 (RC-5) 124

$\pm$

P2 (RC-4) $\quad 66$

$\pm \quad 3$

P3 (RC-3) 56

$\pm \quad 3$

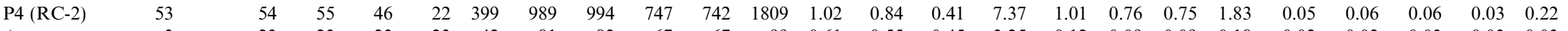
\begin{tabular}{lllllllllllllllllllllllll} 
\pm & 3 & 23 & 23 & 23 & 23 & 42 & 81 & 82 & 67 & 67 & 99 & 0.61 & 0.55 & 0.45 & 3.25 & 0.12 & 0.09 & 0.09 & 0.18 & 0.02 & 0.02 & 0.03 & 0.03 & 0.03 \\
\hline
\end{tabular}

For $k_{i}$ and $f_{i}$, we define $i=8$ for ${ }^{238} \mathrm{U}, i=4$ for ${ }^{234} \mathrm{U}, i=0$ for ${ }^{230} \mathrm{Th}, i=6$ for ${ }^{226} \mathrm{Ra}$ and $i=2$ for ${ }^{232} \mathrm{Th}$ 


\section{Rindlets \\ P constant without ${ }^{232} \mathrm{Th}$}

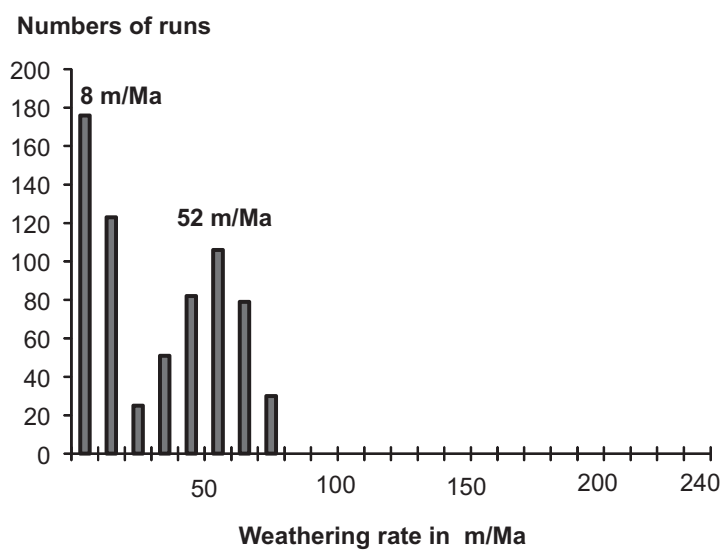

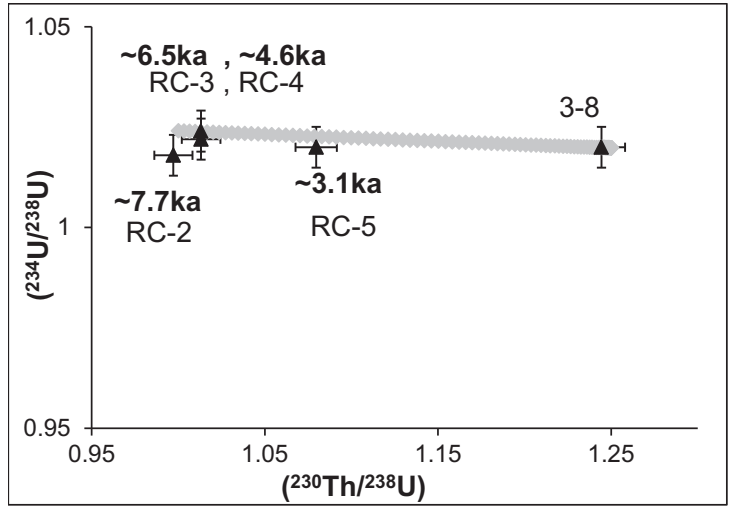

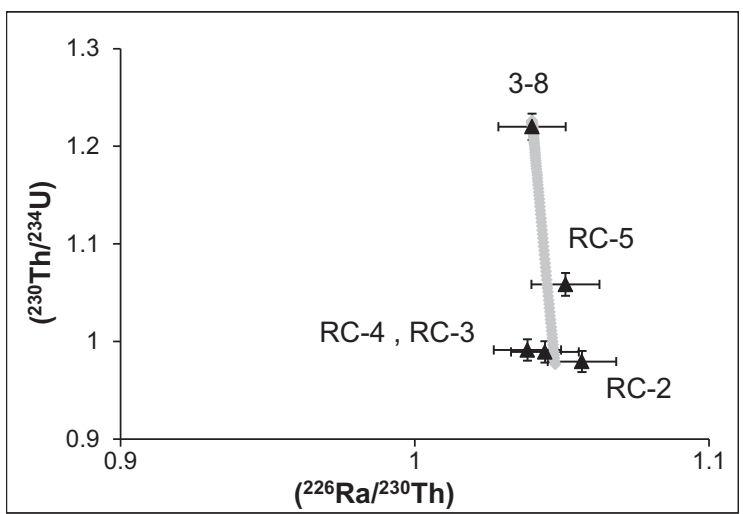

Fig. 8. Measured $\left({ }^{234} \mathrm{U} /{ }^{238} \mathrm{U}\right)$ and $\left({ }^{230} \mathrm{Th} /{ }^{238} \mathrm{U}\right)$ activity ratios and $\left({ }^{230} \mathrm{Th} /{ }^{234} \mathrm{U}\right)$ and $\left({ }^{226} \mathrm{Ra} /{ }^{230} \mathrm{Th}\right)$ activity ratios for the $2003-2004$ rindlets. Dashed line indicates theoretical time evolution of activity ratios of the sample 3-8 with parameters from Table 4 using the model described in the text (in configurations assuming a constant weathering rate for all the profile). Ages reported on the graph are the ages of the different samples relative to the sample 3-8, taken as the initial condition. The histogram gives the occurrence of the different production rates obtained from about 1000 retained runs of the simulation.

eters derived from the models are also consistent with each other. For example, the U input parameters are smaller in the rindlets than in the lower saprolite in accordance with the occurrence of smaller ${ }^{234} \mathrm{U}$ enrichments in the rindlets than in the saprolite. These observations lend confidence to the reliability of the modeling results and hence, to the conclusion that propagation rates of the weathering fronts in the rindlet zone and in the saprolite are very similar. Such a conclusion certainly indicates that the weathering profile has reached a steady-state of functioning for the time period covered by the sampling zone ( $\sim 20$ to $30 \mathrm{ka})$. This is confirmed by the observation that in the $\left({ }^{230} \mathrm{Th} /{ }^{234} \mathrm{U}\right)$ vs. $\left({ }^{226} \mathrm{Ra} /{ }^{230} \mathrm{Th}\right)$ disequilibria diagram, the data points of the most external samples, used for the rate determinations in the rindlet zone and the lower saprolite, plot close to the position of the theoretical steady-state values obtained by assuming time variation in Eqs. (1)-(5) to be equal to zero. This steady-state weathering also agrees with the observation that the propagation rate determined by U-series nuclides, on a time-scale of $10-20 \mathrm{ky}$, is consistent with the present-day weathering rate estimated from streamwater solute fluxes and mineral stoichiometries, which yield short-term chemical weathering rates of $\sim 58$ and $75 \pm 38 \mathrm{~m} / \mathrm{Ma}$ (Table 5).

The Rio Icacos watershed has been the subject of many studies seeking to assess its weathering and/or erosion rates.
The main results and references are given in Table 5. Independently of the observation that the long-term and short term weathering rates are similar in this watershed, the data point out that the local scale regolith production rate inferred in our study from the U-series analysis on a $2-3 \mathrm{~m}$ depth profile is similar to the average rate estimated for the whole watershed. Although such a conclusion has to be confirmed by similar studies in other weathering profiles of the Rio Icacos watershed, it can imply that in contrast to the Shale Hills watershed for example (Ma et al., 2010), the rate of weathering in Rio Icacos watershed is everywhere the same regardless of the position on a hillslope or in the watershed, which in turn would indicate that the weathering system in Rio Icacos basin reached a geomorphologic steady-state. Such a conclusion deducted from the analysis of the outcrop profile, could be questioned, as the profile analyzed in our study may be a complex and landslide covered profile. How to explain that the regolith production rates, recorded in the rindlet zone and in the lower saprolite of the profile, were not perturbed by such a landslide and are still representative of the mean production rate of the regolith at the watershed scale? One explanation would be that this landslide occurred too recently to have disrupted the U-series signals. Alternatively one might suggest that the $2-3 \mathrm{~m}$ thick landslide did not significantly modify the water flow controlling the weathering of the underlying 
Table 5

Compilation of weathering and erosion rates in the Rio Icacos watershed, Luquillo Mountains, Puerto Rico. These data have been derived from approaches based on different methods: mass balance, cosmogenic isotopes, dissolved-solute loss from catchment and U-series isotopes.

\begin{tabular}{lll}
\hline Methods & Weathering rate (m/Ma) & References \\
${ }^{10}$ Be in fluvial sediments long-term mean denudation rates & $43 \pm 15$ & Brown et al. (1995) \\
Mass balance based on water chemistry data from McDowell and Asbury (1994) & $75 \pm 38$ & Brown et al. (1995) \\
Iso-volumetric weathering in the saprolite coupled with watershed solutes fluxes & $\sim 58$ & White et al. (1998) \\
Streamwater fluxes and mineral stoichiometries Chemical denudation velocity & $\sim 65$ & Turner et al. (2003) \\
Sr isotope mass balance at the watershed scale & $68 \pm 4$ & Pett-Ridge et al. (2009) \\
U-series isotope nuclides in a weathering profile & $45 \pm 12$ & This study \\
\hline
\end{tabular}

rocks. However, at this stage of research we cannot yet exclude, as already envisaged in Section 5.2, that the consistency between the regolith production rate and the average weathering rate, estimated for the whole watershed, indicates that the upper part of the profile is not a landslide but corresponds to the upper and in situ part of a classical spheroidal weathering profile. In this case, the above consistency would mean that these different superimposed weathering systems are altered at very similar rates regardless of their location in the profile. The choice between these different scenarios and the reliability of the related conclusions clearly requires the analysis of other profiles, and probably, also a more detailed study of the upper corestone zone of the profile. Whatever the result of these future studies, it seems to be important to emphasize here the necessity to combine U-series studies with other chronometric or geochemical methods providing temporal information on weathering and erosion phenomena. This allows to deeper our research knowledge about the stability of weathering profiles and/or their degree of development (e.g., Ma et al., 2010). Thus, comparison of denudation rates, derived from cosmonuclides chronometry or (U-Th)/He chronometry (Brown et al., 2003; von Blanckenburg, 2005; Braucher et al., 2009), with production rates determined by U-series nuclides could become an important approach in a near future to estimate the balance between mean regolith production and erosion rates through time.

\subsubsection{Implications for the application of $U$-series methodology}

The results of our study demonstrate that the budget of the U, Th and Ra nuclides in the rocks of a weathering profile can be reduced to a relatively simple mathematical formalism which allows to derive realistic regolith formation rates from whole rock data collected along the weathering profile. This confirms, thereby, the usefulness of this method for dating complex weathering processes such as spheroidal weathering.

Nevertheless, the resulting rates are entirely "model dependent". Among others, the model implicitly assumes a congruent weathering system, at least for the U-series nuclides. If this is not the case, the model equations are no longer applicable. In the case of our study it is important to draw attention to the observation that the use of ${ }^{232} \mathrm{Th}$ and hence of $\left({ }^{238} \mathrm{U} /{ }^{232} \mathrm{Th}\right)$ and $\left({ }^{230} \mathrm{Th} /{ }^{232} \mathrm{Th}\right)$ ratios together with the ${ }^{238} \mathrm{U}-{ }^{234} \mathrm{U}-{ }^{230} \mathrm{Th}-{ }^{226} \mathrm{Ra}$ nuclides provides inferior fits to the data than simulations with only ${ }^{238} \mathrm{U}-{ }^{234} \mathrm{U}-{ }^{230} \mathrm{Th}-{ }^{226} \mathrm{Ra}$. This could be the result of differential weathering. Trace and major element data on saprolite and rindlets indeed support the occurrence of such a process in the Puerto Rico System (White et al., 1998; Buss et al., 2008). Since ${ }^{232}$ Th and ${ }^{238} \mathrm{U}$ are differently enriched in the different rock-forming minerals and since in the same mineral ${ }^{232} \mathrm{Th}$ occupies other crystallographic sites than ${ }^{238} \mathrm{U}$, not only the quartz diorite but all magmatic rocks contain minerals with different $\left({ }^{238} \mathrm{U} /{ }^{232} \mathrm{Th}\right)$ and $\left({ }^{230} \mathrm{Th} /{ }^{232} \mathrm{Th}\right)$ ratios. Weathering of minerals with different $\left({ }^{238} \mathrm{U} /{ }^{232} \mathrm{Th}\right)$ and $\left({ }^{230} \mathrm{Th} /{ }^{232} \mathrm{Th}\right)$ ratios, however, might induce "apparent fractionations" of the ${ }^{230} \mathrm{Th}-{ }^{232} \mathrm{Th}$ and partly of the ${ }^{238} \mathrm{U}-{ }^{232} \mathrm{Th}$ nuclides at the whole rock scale, which are not only the consequence of the chemical fractionation between uranium and thorium and time, but also of the proportion of the minerals involved in the weathering process. Thus, the use of ${ }^{232} \mathrm{Th}$ necessitates the additional introduction of the specific mobility parameters of these different mineral phases into the model equations. Given the number of parameters to be estimated, this renders the modeling more or less impossible by the approach proposed in Section 3.1.

It logically follows the question why can the variations of the ${ }^{238} \mathrm{U}-{ }^{234} \mathrm{U}-{ }^{230} \mathrm{Th}-{ }^{226} \mathrm{Ra}$ data be conformed, at least in the Puerto Rico system, to a congruent weathering model (for U-series nuclides) despite differential weathering processes, whereas they cannot when ${ }^{232} \mathrm{Th}$ is additionally used. One solution, probably the less likely one, would be that the differential dissolution would not affect the main minerals controlling the budget of uranium, but mainly Th enriched minerals. A more likely explanation would be that differential weathering becomes more evident when instead of nuclides from only one $U$ radioactive decay series, nuclides from all three series (including ${ }^{232} \mathrm{Th}$ ) are used. This might be simply because the leaching rates of the different U-series nuclides are not so different from one mineral to another and hence the effect of differential weathering mainly appears with the modification of the $\left({ }^{230} \mathrm{Th} /{ }^{232} \mathrm{Th}\right)$ activity ratios due to the changes of the proportions of primary minerals being involved in the weathering process. Choosing between these different possibilities requires a better knowledge of the leaching rates of the different rock-forming minerals and/or to the use of some statistical tests analyzing the model sensitivity to the differential weathering process; this is clearly out of the scope of this work.

Nevertheless, the results clearly indicate that even under complex differential weathering conditions, the radioactive disequilibrium between the nuclides of the ${ }^{238} \mathrm{U}$-series can still be interpreted in terms of congruent weathering. Thus, it appears that the use of the ${ }^{238} \mathrm{U}-{ }^{234} \mathrm{U}-{ }^{230} \mathrm{Th}$ nuclides together with the ${ }^{226} \mathrm{R}$ a nuclide allows for a better determina- 
tion of the regolith production rate than together with the ${ }^{232}$ Th nuclide.

\section{CONCLUSIONS}

The geochemical and isotopic ( $\mathrm{Sr}, \mathrm{Nd}, \mathrm{U}$-series nuclides) data of a 2-m thick spheroidal weathering profile indicate that in this profile, the weathering front does not progress continuously from the top to the base of the profile. This is probably due to an upper unit comprised of landslide debris, although it may also be due to the spheroidal nature of the bedrock weathering system: the weathering proceeds in this case along preferential surfaces of water circulation in the rock, inherited from the 3D network of pre-existing bedrock joint planes. The consequence is that the determination of weathering rates by ${ }^{238} \mathrm{U}-{ }^{234} \mathrm{U}-{ }^{230} \mathrm{Th}-{ }^{226} \mathrm{Ra}$ disequilibrium is only possible in the lower part of the profile, which is composed of the corestone, the related rindlet system and the saprolite in contact with these rindlets.

Interpretation of the variation of U-series nuclides in the rindlet-saprolite system by using classical loss and gain models for describing the mobility of radionuclides during weathering, allows estimation of similar propagation rates of the weathering front $(\sim 45 \mathrm{~m} / \mathrm{Ma})$ in rindlets and saprolite. The consistency of the derived weathering rate with the average weathering and erosion rates determined by other methods for the whole watershed argues again, that in the Rio Icacos watershed, the weathering system has reached a geomorphic steady-state. Our results further indicate that even in environments with differential weathering, such as observed for the Puerto Rico site, the radioactive disequilibrium between the nuclides of a single radioactive series (here ${ }^{238} \mathrm{U}$-series) can still be interpreted in terms of a congruent weathering scenario. They also illustrate the utility of combining the analysis of ${ }^{226} \mathrm{Ra}^{230} \mathrm{Th}$ disequilibria with the analysis of ${ }^{238} \mathrm{U}-{ }^{234} \mathrm{U}-{ }^{230} \mathrm{Th}$ disequilibria to constrain the weathering rates in such context. This study should stimulate future development of ${ }^{238} \mathrm{U}-{ }^{234} \mathrm{U}-{ }^{230} \mathrm{Th}-{ }^{226} \mathrm{Ra}$ nuclides for the determination of weathering rates in weathering profiles with variable geological or environmental parameters.

\section{ACKNOWLEDGMENTS}

A. White and R. Fletcher are thanked for their help during sampling campaigns and their discussion on weathering processes and spheroidal weathering. Th. Perrone is warmly acknowledged for some $\mathrm{Sr}$ and the $\mathrm{Nd}$ isotopic measurements on the Neptune and the Triton (Strasbourg) and René Boutin for the analyses of the major and trace element concentrations. We thank very much the associate Editor S. Krishnaswami and three anonymous reviewers for their comments and suggestions, which helped to improve the manuscript. Discussions on the Puerto Rico data with J. Honnorez, M. Granet, D. Lemarchand, S. Rihs, and MC Pierret were also very helpful. This work has been supported by the funding of a Ph.D. scholarship from the Region Alsace and the CNRS (BDI), France, to E. Blaes, and was funded by the Région Alsace, France, and the CPER 2003-2013 "REALISE". SLB acknowledges support in part from DOE Grant DE-FG02-05ER15675, as well as some logistical support contributed by the NSF-supported Luquillo Critical Zone Observatory (EAR 0722476). H.L.B. acknowledges support of the USGS Water Energy and Biogeochemical Budgets (WEBB) project and the USGS National Research Program. A.D. acknowledges an
Australia Research Council Future Fellowship (FT0990447). The work has been also supported by the SoilTrec European Program. This is an EOST-LHyGeS contribution.

\section{APPENDIX A1. SOLVING THE SYSTEM OF EQS. (A1)-(A5)}

We describe here the construction of the bound constrained optimization algorithm used to perform the calculation of the leaching rate constants: $k_{238}, k_{234}, k_{230}, k_{226}$ and $k_{232}$, the input flux constants: $f_{238}, f_{234}, f_{230}, f_{226}$ and $f_{232}$ for each nuclide and the migration rates of the weathering front $\mathrm{p}$. The model used is based on that presented by Dequincey et al. (2002) and Dosseto et al. (2008), modified by adding a mobility for ${ }^{230} \mathrm{Th}$, and ${ }^{232} \mathrm{Th}$, and by adding the ${ }^{226} \mathrm{Ra}$, the direct daughter of ${ }^{230} \mathrm{Th}$. Solutions of the ordinary differential equation Eqs. (A1)-(A5) system are given in Section A2. They were determined using Laplace transformations and the symbolic computer algebra system: Maxima 5.18.1.

For the lower saprolite and the rindlet zone used for weathering rate determination, measured $\left({ }^{234} \mathrm{U} /{ }^{238} \mathrm{U}\right),\left({ }^{230} \mathrm{Th} /{ }^{238} \mathrm{U}\right)$, $\left({ }^{226} \mathrm{Ra} /{ }^{230} \mathrm{Th}\right),\left({ }^{238} \mathrm{U} /{ }^{232} \mathrm{Th}\right)$ and $\left({ }^{230} \mathrm{Th} /{ }^{232} \mathrm{Th}\right)$ ratios in each sample are used to constrain the parameters of the model. Two different solving configurations are envisaged: the first one, without using ${ }^{232} \mathrm{Th}$ mobility, and hence, only $\left({ }^{234} \mathrm{U} /{ }^{238} \mathrm{U}\right),\left({ }^{230} \mathrm{Th} /{ }^{238} \mathrm{U}\right)$ and $\left({ }^{226} \mathrm{Ra} /{ }^{230} \mathrm{Th}\right)$ ratios are modeled; the second one includes ${ }^{232} \mathrm{Th}$ mobility and $\left({ }^{234} \mathrm{U} /{ }^{238} \mathrm{U}\right)$, $\left({ }^{230} \mathrm{Th} /{ }^{238} \mathrm{U}\right),\left({ }^{226} \mathrm{Ra} /{ }^{230} \mathrm{Th}\right),\left({ }^{238} \mathrm{U} /{ }^{232} \mathrm{Th}\right)$ and $\left({ }^{230} \mathrm{Th} /{ }^{232} \mathrm{Th}\right)$ activity ratios are modeled. For the weathering rate $P$, two cases have been studied: one case is based on the assumption that the regolith production rate $P$ is considered to be constant through each profile. The other assumes that $P$ can vary for each sample in the saprolite and rindlet zone (one $P$ for each sample). Instead of the measured bedrock samples, the deepest sample from each zone was used to represent the reference samples and hence used to give the initial conditions.

The objective function is built by starting from a least square formulation using as input values measured radionuclide ratios with simple bounds on the variables $\mathbf{x}=\left(p ; k_{238}\right.$; $\left.k_{234} ; k_{230} ; k_{226} ; k_{232} ; f_{238} ; f_{234} ; f_{230} ; f_{226} ; f_{232}\right)$. The aim of constraint optimization was to find a solution (parameters) that minimizes the sum of the square of the difference between observed and modeled values. For the first iterate, $\mathbf{x}_{\mathbf{0}}$ is randomly computed within lower and upper bound. The algorithm uses a large-scale bound-constrained optimization solver: L-BFGS-B (Byrd et al., 1995; Zhu and Byrd, 1997; Morales and Nocedal, 2011). It is a limited-memory quasiNewton code (Broyden-Fletcher-Goldfarb-Shanno approximation of the Hessian matrix) for bound-constrained optimization, i.e. for problems where the only constraints are of the form $\boldsymbol{x}_{\boldsymbol{l}} \leqslant \boldsymbol{x} \leqslant \boldsymbol{x}_{\boldsymbol{u}}$. The vectors $\mathbf{x}_{\boldsymbol{l}}$ and $\boldsymbol{x}_{\boldsymbol{u}}$ are the vector of lower and upper bounds on the variables, respectively, and we allow either of them to have components $-\infty$ or $+\infty$. The gradients of the objective function related to each variables are numerically computed using a high precision numerical differentiation scheme (sixth order extrapolation rule).

The model calculation was performed 1000 times to obtain parameter solutions for different random values for $\mathbf{x}_{\mathbf{0}}$. 
The model calculates output parameters such that they fit the observed activity ratios with approximately less than $1 \%$ error. In all of our numerical studies, the number of model equation is equal to or greater than the number of unknown parameters: the system is over-determined. saprolite transformation in the Rio Icacos watershed, Puerto Rico. Geochim. Cosmochim. Acta 73, A128.

Boulad A. P., Muller J.-P. and Bocquier G. (1977) Essai de détermination de l'âge et de la vitesse d'altération d'un sol ferrallitique camerounais à l'aide de la méthode du déséquilibre radioactif uranium-thorium. Sci. Géol. Bull. 30, 175-188.

\section{APPENDIX A2. ANALYTICAL SOLUTIONS OF THE ORDINARY DIFFERENTIAL EQUATIONS EQS. (A1)-(A5)}

(N.B.: The activity of each nuclide is determined by multiplying the solution by the decay constant of the nuclide)

$$
\begin{aligned}
& { }^{238} \mathrm{U}(t)=\frac{f_{238}{ }^{238} \mathrm{U}_{0}}{\alpha_{238}}+e^{-\lambda_{238} t}\left({ }^{238} \mathrm{U}_{0}-\frac{f_{238}{ }^{238} \mathrm{U}_{0}}{\alpha_{238}}\right) \\
& { }^{234} \mathrm{U}(t)=\frac{1}{\alpha_{234}}\left(f_{234}{ }^{234} \mathrm{U}_{0}+\lambda_{238} \frac{f_{238}{ }^{238} \mathrm{U}_{0}}{\alpha_{238}}\right)+e^{-\alpha_{238}}\left({ }^{238} \mathrm{U}_{0}-\frac{f_{238}{ }^{238} \mathrm{U}_{0}}{\alpha_{238}}\right) \frac{\lambda_{238}}{\alpha_{234}-\alpha_{238}} \\
& +e^{-\alpha_{234}^{t}}\left({ }^{234} \mathrm{U}_{0}-\frac{f_{234}{ }^{234} \mathrm{U}_{0}}{\alpha_{234}}+\left({ }^{238} \mathrm{U}_{0}-\frac{f_{238}{ }^{238} \mathrm{U}_{0}}{\alpha_{234}}\right) \frac{\lambda_{238}}{\alpha_{238}-\alpha_{234}}\right) \\
& { }^{230} \operatorname{Th}(t)=\frac{1}{\alpha_{230}}\left(f_{230}{ }^{230} \mathrm{Th}_{0}+\frac{\lambda_{234}}{\alpha_{234}}\left(f_{234}{ }^{234} \mathrm{U}_{0}+\lambda_{238} \frac{f_{238}{ }^{238} \mathrm{U}_{0}}{\alpha_{238}}\right)\right)+e^{-\alpha_{238} t}\left({ }^{238} \mathrm{U}_{0}-\frac{f_{238}{ }^{238} \mathrm{U}_{0}}{\alpha_{238}}\right) \frac{\lambda_{238} \lambda_{234}}{\left(\alpha_{234}-\alpha_{238}\right)\left(\alpha_{230}-\alpha_{238}\right)} \\
& +e^{-\alpha_{234}^{t}}\left({ }^{234} \mathrm{U}_{0}-\frac{f_{234}{ }^{234} \mathrm{U}_{0}}{\alpha_{234}}+\left({ }^{238} \mathrm{U}_{0}-\frac{f_{238}{ }^{238} \mathrm{U}_{0}}{\alpha_{234}}\right) \frac{\lambda_{238}}{\alpha_{238}-\alpha_{234}}\right) \\
& +e^{-\alpha_{230} t}\left({ }^{230} \mathrm{Th}_{0}-\frac{f_{230}{ }^{230} \mathrm{Th}_{0}}{\alpha_{230}}+\frac{\lambda_{234}}{\alpha_{234}-\alpha_{230}}\left({ }^{234} \mathrm{U}_{0}-\frac{f_{234}{ }^{234} \mathrm{U}_{0}}{\alpha_{230}}+\left({ }^{238} \mathrm{U}_{0}-\frac{f_{238}{ }^{238} \mathrm{U}_{0}}{\alpha_{230}}\right) \frac{\lambda_{238}}{\alpha_{238}-\alpha_{230}}\right)\right) \\
& { }^{226} \operatorname{Ra}(t)=\frac{1}{\alpha_{226}}\left(f_{226}{ }^{226} \mathrm{Ra}_{0}+\frac{\lambda_{230}}{\alpha_{230}}\left(f_{230}{ }^{230} \mathrm{Th}_{0}+\frac{\lambda_{234}}{\alpha_{234}}\left(f_{234}{ }^{234} \mathrm{U}_{0}+\lambda_{238} \frac{f_{238}{ }^{238} \mathrm{U}_{0}}{\alpha_{238}}\right)\right)\right)+e^{-\alpha_{238} t}\left({ }^{238} \mathrm{U}_{0}-\frac{f_{238}{ }^{238} \mathrm{U}_{0}}{\alpha_{238}}\right) \frac{\lambda_{238} \lambda_{234} \lambda_{230}}{\left(\alpha_{234}-\alpha_{238}\right)\left(\alpha_{230}-\alpha_{238}\right)\left(\alpha_{226}-\alpha_{238}\right)} \\
& +e^{-\alpha_{234}^{\prime}}\left({ }^{234} \mathrm{U}_{0}-\frac{f_{234}{ }^{234} \mathrm{U}_{0}}{\alpha_{234}}+\left({ }^{238} \mathrm{U}_{0}-\frac{f_{233}{ }^{238} \mathrm{U}_{0}}{\alpha_{234}}\right) \frac{\lambda_{238}}{\alpha_{238}-\alpha_{234}}\right) \frac{\lambda_{234} \lambda_{230}}{\left(\alpha_{230}-\alpha_{234}\right)\left(\alpha_{226}-\alpha_{234}\right)} \\
& +e^{-\alpha_{230} t}\left({ }^{230} \mathrm{Th}_{0}-\frac{f_{230}{ }^{230} \mathrm{Th}_{0}}{\alpha_{230}}+\frac{\lambda_{234}}{\alpha_{234}-\alpha_{230}}\left({ }^{234} \mathrm{U}_{0}-\frac{f_{234}{ }^{234} \mathrm{U}_{0}}{\alpha_{230}}+\left({ }^{238} \mathrm{U}_{0}-\frac{f_{238}{ }^{238} \mathrm{U}_{0}}{\alpha_{230}}\right) \frac{\lambda_{238}}{\alpha_{238}-\alpha_{230}}\right)\right) \frac{\lambda_{230}}{\left(\alpha_{226}-\alpha_{230}\right)\left(\alpha_{226}-\alpha_{230}\right)} \\
& +e^{-\alpha_{226} t}\left({ }^{226} \mathrm{Ra}_{0}-\frac{f_{226}{ }^{226} \mathrm{Ra}_{0}}{\alpha_{226}}+\frac{\lambda_{230}}{\alpha_{230}-\alpha_{226}}\left({ }^{230} \mathrm{Th}_{0}-\frac{f_{230}{ }^{230} \mathrm{Th}_{0}}{\alpha_{226}}+\frac{\lambda_{234}}{\alpha_{234}-\alpha_{226}}\left({ }^{234} \mathrm{U}_{0}-\frac{f_{234}{ }^{234} \mathrm{U}_{0}}{\alpha_{226}}+\left({ }^{238} U_{0} \frac{f_{238}{ }^{238} \mathrm{U}_{0}}{\alpha_{226}}\right) \frac{\lambda_{238}}{\alpha_{238}-\alpha_{226}}\right)\right)\right) \\
& { }^{232} \operatorname{Th}(t)=\frac{f_{232}{ }^{232} \mathrm{Th}_{0}}{\alpha_{232}}+e^{-\lambda_{232} t}\left({ }^{232} \mathrm{Th}_{0}-\frac{f_{232}{ }^{232} \mathrm{Th}_{0}}{\alpha_{232}}\right)
\end{aligned}
$$

Here, we define

$l \alpha_{238}=\lambda_{238}+k_{238} \alpha_{234}=\lambda_{234}+k_{234} \alpha_{230}=\lambda_{230}+k_{230} \alpha_{226}=\lambda_{226}+k_{226} \alpha_{232}=\lambda_{232}+k_{232}$

and ${ }^{238} \mathrm{U}_{0},{ }^{234} \mathrm{U}_{0},{ }^{230} \mathrm{Th}_{0},{ }^{226} \mathrm{Ra}_{0}$ and ${ }^{232} \mathrm{Th}_{0}$ are the initial number of atoms of ${ }^{238} \mathrm{U},{ }^{234} \mathrm{U},{ }^{230} \mathrm{Th},{ }^{226} \mathrm{Ra}$ and ${ }^{232} \mathrm{Th}$ respectively per gram of starting material.

\section{APPENDIX B. SUPPLEMENTARY DATA}

Supplementary data associated with this article can be found, in the online version, at http://dx.doi.org/10.1016/ j.gca.2012.09.037.

\section{REFERENCES}

Akovali Y. A. (1994) Nuclear data sheets for $\mathrm{A}=234$. Nucl. Data Sheets 71, 18.

Aubert D., Stille P. and Probst A. (2001) REE fractionation during granite weathering and removal by waters and suspended loads: $\mathrm{Sr}$ and $\mathrm{Nd}$ isotopic evidence. Geochim. Cosmochim. Acta $\mathbf{6 5}$, 387-406.

Banwart S. et al. (2011) Soil processes and functions in critical zone observatories: Hypotheses and experimental design. Vadose Zone J. 10, 974-987.

Blaes E., Chabaux F., Pelt E., Dosseto A., Buss H., White A. and Brantley S. (2009) U-series constraints for the rate of bedrock-
Bourdon B., Turner S., Henderson G. M., Lundstrom C. C. (2003) Introduction to U-series geochemistry: In U-series geochemistry. In Reviews in Mineralogy and Geochemistry, vol. 52, (eds. B. Bourdon, S. Turner, G. Henderson, and C. C. Lundstrom). 656p. Min. Soc. Am. Geochem. Soc. 1-21.

Brantley S. L. (2008) Understanding soil time. Science 321, 1454 1455.

Brantley S. L., Goldhaber M. B. and Ragnarsdottir K. V. (2007) Crossing disciplines and scales to understand the critical zone. Elements 3, 307-314.

Braucher R., Del Castillo P., Siame L., Hydy A. J. and Bourlès D. L. (2009) Determination of both exposure time and denudation rate from an in situ-produced $10 \mathrm{Be}$ depth profile: A mathematical proof of uniqueness. Model sensitivity and applications to natural cases. Quat. Geochronol. 4, 56-67.

Brown E. T., Stallard R. F., Larsen M. C., Raisbeck G. M. and Yiou F. (1995) Denudation rates determined from the accumulation of in situ-produced $10 \mathrm{Be}$ in the luquillo experimental forest, Puerto Rico. Earth Planet. Sci. Lett. 129, 193-202. 
Brown E. T., Colin F. and Bourlès D. (2003) Quantitative evaluation of soil processes using in situ-produced cosmogenic nuclides. C. R. Geosci. 335, 1161-1171.

Buss H. L., Sak P. B., Webb S. M. and Brantley S. L. (2008) Weathering of the Rio Blanco quartz diorite, Luquillo Mountains, Puerto Rico: Coupling oxidation, dissolution, and fracturing. Geochim. Cosmochim. Acta 72, 4488-4507.

Byrd R. H., Lu P. and Nocedal J. (1995) A limited memory algorithm for bound constrained optimization. SIAM J. Sci. Stat. Comput. 16(5), 1190-1208.

Chabaux F. and Allègre C. J. (1994) ${ }^{238} \mathrm{U}^{230}{ }^{23} \mathrm{Th}-{ }^{226} \mathrm{Ra}$ disequilibria in volcanics: A new insight into melting conditions. Earth Planet. Sci. Lett. 126, 61-74.

Chabaux F., Othman D. B. and Birck J. L. (1994) A new RaBa chromatographic separation and its application to Ra massspectrometric measurement in volcanic rocks. Chem. Geol. 114, 191-197.

Chabaux F., Riotte J. and Dequincey O. (2003a) U-Th-Ra fractionation during weathering and river transport. Rev. Mineral. Geochem. 52, 533-576.

Chabaux F., Dequincey O., Lévèque J.-J., Leprun J.-C., Clauer N., Riotte J. and Paquet H. (2003b) Tracing and dating recent chemical transfers in weathering profiles by trace-element geochemistry and ${ }^{238} \mathrm{U}-{ }^{234} \mathrm{U}-{ }^{230} \mathrm{Th}$ disequilibria: The example of the Kaya lateritic toposequence (Burkina-Faso). C. $R$. Geosci. 335, 1219-1231.

Chabaux F., Bourdon B. and Riotte J. (2008) U-series geochemistry in weathering profiles, river waters and lakes. In U/Th Series Radionuclides in Aquatic Systems, Radioactivity in the Environment, vol. 13 (eds. S. Krishnaswami and J. K. Cochran). Elsevier, pp. 49-104.

Chabaux F., Ma L., Stille P., Pelt E., Granet M., Lemarchand D., Roupert R. diC. and Brantley S. L. (2011) Determination of chemical weathering rates from $\mathrm{U}$ series nuclides in soils and weathering profiles: Principles, applications and limitations. Appl. Geochem. 26, S20-S23.

Cheng H., Edwards R. L., Hoff J., Gallup C. D., Richards D. A. and Asmerom Y. (2000) The half-lives of uranium-234 and thorium-230. Chem. Geol. 169, 17-33.

Chmeleff J. (2005) Les déséquilibres radioactifs ${ }^{238} \mathrm{U}-{ }^{230} \mathrm{Th}-{ }^{226} \mathrm{Ra}$ : Discussions sur les sources et processus responsables du volcanisme de la Cordillère des Andes et sur ladéglaciation en Islande. Thèse de doctorat, Université Blaise Pascal.

Cox D. P., Marvin R. F., M'Gonigle J. W., McIntyre D. H. and Rogers C. L. (1977) Potassium-argon geochronology of some metamorphic, igneous, and hydrothermal events in Puerto Rico and the Virgin Islands. U.S. Geol. Surv. J. Res. 5, 689-703.

Dequincey O., Chabaux F., Clauer N., Liewig N. and Muller J.-P. (1999) Dating of weathering profiles by radioactive disequilibria: Contribution of the study of authigenic mineral fractions. C. R. Acad. Sci. Ser. IIA - Earth Planet. Sci. 328, 679-685.

Dequincey O., Chabaux F., Clauer N., Sigmarsson O., Liewig N. and Leprun J.-C. (2002) Chemical mobilizations in laterites: Evidence from trace elements and ${ }^{238} \mathrm{U}-{ }^{234} \mathrm{U}-{ }^{230} \mathrm{Th}$ disequilibria. Geochim. Cosmochim. Acta 66, 1197-1210.

Dequincey O., Chabaux F., Leprun J.-C., Paquet H., Clauer N. and Larque P. (2006) Lanthanide and trace element mobilization in a lateritic toposequence: Inferences from the Kaya laterite in Burkina Faso. Eur. J. Soil Sci. 57, 816-830.

Dia A., Chauvel C., Bulourde M. and Gérard M. (2006) Eolian contribution to soils on Mount Cameroon: Isotopic and trace element records. Chem. Geol. 226, 232-252.

Di Chiara Roupert R., Schäfer G., Ackerer P., Quintard M. and Chavent G. (2010) Construction of three-phase data to model multiphase flow in porous media: Comparing an optimization approach to the finite element approach. C. R. Geosci. 342, 855-863. http://dx.doi.org/10.1016/j.crte.2010.07.004.

Dosseto A., Turner S. P. and Chappell J. (2008) The evolution of weathering profiles through time: New insights from uraniumseries isotopes. Earth Planet. Sci. Lett. 274, 359-371.

Dosseto A., Buss H. and Suresh P. O. (2012) Rapid regolith formation over volcanic bedrock and implications for landscape evolution. Earth Planet. Sci. Lett. 337, 47-55.

Doucet F. J. and Carignan J. (2001) Atmospheric Pb isotopic composition and trace metal concentration as revealed by epiphytic lichens: An investigation related to two altitudinal sections in Eastern France. Atmos. Environ. 35, 3681-3690.

Ferrier K. L., Kirchner J. W., Riebe C. S. and Finkel R. C. (2010) Mineral-specific chemical weathering rates over millennial timescales: Measurements at Rio Icacos, Puerto Rico. Chem. Geol. 277, 101-114.

Fletcher R. C., Buss H. L. and Brantley S. L. (2006) A spheroidal weathering model coupling porewater chemistry to soil thicknesses during steady-state denudation. Earth Planet. Sci. Lett. 244, 444-457.

Fletcher R. C. and Brantley S. L. (2010) Reduction of bedrock blocks as corestones in the weathering profile: Observations and model. Am. J. Sci. 310, 131-164.

Frost, C. D., Schellekens, J. H. and Smith, A. L., (1998), Nd, Sr and $\mathrm{Pb}$ isotopic characterization of Cretaceous and Paleogene volcanic and plutonic island arc rocks from Puerto Rico: in Lidiak, E.G. and Larue, D.K., ed., Tectonics and geochemistry of the northeastern Caribbean, Geol. Soc. Am. Spec. Pap. 322, p.123-132.

Ghaleb B., Pons-Branchu E. and Deschamps P. (2004) Improved method for radium extraction from environmental samples and its analysis by thermal ionization mass spectrometry. J. Anal. At. Spectrom. 19, 906-910.

Granet M., Chabaux F., Stille P., France-Lanord C. and Pelt E. (2007) Time-scales of sedimentary transfer and weathering processes from U-series nuclides: Clues from the Himalayan rivers. Earth Planet. Sci. Lett. 261, 389-406.

Granet M., Chabaux F., Stille P., Dosseto A., France-Lanord C. and Blaes E. (2010) U-series disequilibria in suspended river sediments and implication for sediment transfer time in alluvial plains: The case of the Himalayan rivers. Geochim. Cosmochim. Acta 74, 2851-2865.

Hansen R. O. and Stout P. R. (1968) Isotopic distribution of uraniumand thorium in soils. Soil Sci. 105, 44-50.

Innocent C. et al. (2004) Intercomparison of new Th isotopic standards: preliminary results. 14th Goldschmidt Conference. Copenhagen, Denmark.

Ivanovich, M. and Harmon, R. S. (eds.) (1992) Uranium-Series Disequilibrium: Application to Earth, Marine, and Environmental Sciences. Clarendon Press, Oxford.

Jones L. M. and Kesler S. E. (1980) Strontium isotopic geochemistry of intrusive rocks, Puerto Rico, Greater Antilles. Earth Planet. Sci. Lett. 50, 219-224.

Lahd Geagea M., Stille P., Millet M. and Perrone T. (2007) REE characteristics and $\mathrm{Pb}, \mathrm{Sr}$ and $\mathrm{Nd}$ isotopic compositions of steel plant emissions. Sci. Total Environ. 373, 404-419.

Ma L., Chabaux F., Pelt E., Blaes E., Jin L. and Brantley S. L. (2010) Regolith production rates calculated with uranium-series isotopes at Susquehanna/Shale Hills Critical Zone Observatory. Earth Planet. Sci. Lett. 297, 211-225.

Ma L., Chabaux F., Pelt E., Granet M., Sak P., Gaillardet J., Lebedeva M. and Brantley S. B. (2012) The effect of curvature on weathering rind formation: evidence from U-series isotopes in basaltic andesite weathering clasts in Guadeloupe. Geochimica et Cosmochimica Acta 80, 92-107. 
Ma L., Chabaux F., Pelt E., Granet M., Sak P. B., Gaillardet J., Labedeva M. and Brantley S. L. (2011) The effect of curvature on weathering rind formation: Evidence from Uranium-series isotopes in basaltic andesite weathering clasts in Guadeloupe. Geochim. Cosmochim. Acta (in revision).

McDowell W. H., Sánchez C. G., Asbury C. E. and Ramos Pérez C. R. (1990) Influence of sea salt aerosols and long range transport on precipitation chemistry at El Verde, Puerto Rico. Atmos. Environ. A-Gen. Top. 24, 2813-2821.

McDowell W. H. and Asbury C. E. (1994) Export of carbon, nitrogen, and major ions from three tropical montane watersheds. Limnol. Oceanogr. 39, 111-125.

Mathieu D., Bernat M. and Nahon D. (1995) Short-lived U and Th isotope distribution in a tropical laterite derived from Granite (Pitinga river basin, Amazonia, Brazil): Application to assessment of weathering rate. Earth Planet. Sci. Lett. 136, 703-714.

Millot R., Gaillardet J., Dupré B. and Allègre C. J. (2002) The global control of silicate weathering rates and the coupling with physical erosion: New insights from rivers of the Canadian Shield. Earth Planet. Sci. Lett. 196, 83-98.

Morales J. L. and Nocedal J. (2011) Remark on "Algorithm 778: L-BFGS-B: Fortran subroutines for large-scale bound constrained optimization". SIAM J. Sci. Stat. Comput. 16(5), 1190-1208.

Murphy S. F., Brantley S. L., Blum A. E., White A. F. and Dong H. (1998) Chemical weathering in a tropical watershed, Luquillo Mountains, Puerto Rico: II. Rate and mechanism of biotite weathering. Geochim. Cosmochim. Acta 62, 227-243.

Pelt E. (2007) Datation des processus d'altération par l'étude des déséquilibres ${ }^{238} \mathrm{U}-{ }^{234} \mathrm{U}-{ }^{230} \mathrm{Th}-{ }^{226} \mathrm{Ra}$. Thèse de l'Université Louis Pasteur, Strasbourg.

Pelt E., Chabaux F., Innocent C., Navarre-Sitchler A. K., Sak P. B. and Brantley S. L. (2008) Uranium-thorium chronometry of weathering rinds: Rock alteration rate and paleo-isotopic record of weathering fluids. Earth Planet. Sci. Lett. 276, 98-105.

Pelt E., Chabaux F., Innocent C., Ghaleb B. and Stille P. (2011) Influence of dust deposits to the budget of U-series nuclides in mount Cameroon basaltic soils. Min. Mag. 75, 1617.

Pett-Ridge J. C., Monastra V. M., Derry L. A. and Chadwick O. A. (2007) Importance of atmospheric inputs and Fe-oxides in controlling soil uranium budgets and behavior along a Hawaiian chronosequence. Chem. Geol. 244, 691-707.

Pett-Ridge J. C., Derry L. A. and Kurtz A. C. (2009a) Sr isotopes as a tracer of weathering processes and dust inputs in a tropical granitoid watershed, Luquillo Mountains, Puerto Rico. Geochim. Cosmochim. Acta 73, 25-43.

Pett-Ridge J. C., Derry L. A. and Barrows J. K. (2009b) Ca/Sr and ${ }^{87} \mathrm{Sr} /{ }^{86} \mathrm{Sr}$ ratios as tracers of $\mathrm{Ca}$ and $\mathrm{Sr}$ cycling in the Rio Icacos watershed, Luquillo Mountains, Puerto Rico. Chem. Geol. 267, $32-45$.

Pin C. and Zalduegui J. S. (1997) Sequential separation of light rare-earth elements, thorium and uranium by miniaturized extraction chromatography: Application to isotopic analyses of silicate rocks. Anal. Chim. Acta 339, 79-89.

Pourcelot L., Louvat D., Gauthier-Lafaye F. and Stille P. (2003) Formation of radioactivity enriched soils in mountain areas. $J$. Environ. Radioact. 68, 215-233.

Riebe C. S., Kirchner J. W. and Finkel R. C. (2003) Long-term rates of chemical weathering and physical erosion from cosmogenic nuclides and geochemical mass balance. Geochim. Cosmochim. Acta 67, 4411-4427.

Rihs S., Prunier J., Thien B., Lemarchand D., Pierret M. C. and Chabaux F. (2011) Using short-lived nuclides of the U and Th- series to probe the kinetic of colloid migration in forested soils. Geochim. Cosmochim. Acta 75, 7707-7724.

Riotte J. and Chabaux F. (1999) ${ }^{234} \mathrm{U} /{ }^{238} \mathrm{U}$ ) activity ratios in freshwaters as tracers of hydrological processes: The Strengbach watershed (Vosges, France. Geochim. Cosmochim. Acta 63, 1263-1275.

Rosholt J., Doe B. and Tatsumoto M. (1966) Evolution of the isotopic composition of uranium and thorium in soil profiles. Geol. Soc. Am. Bull. 77, 987-1004.

Rosholt J. (1982) Mobilization and weathering. In Uranium Series Disequilibrium: Application to Environmental Problems (eds. Ivanovich and Harmon). Oxford Sciences Publications, pp. 167-180.

Rydell H. S. and Prospero J. M. (1972) Uranium and thorium concentrations in wind-borne Saharan dust over the Western Equatorial North Atlantic Ocean. Earth Planet. Sci. Lett. 14, 397-402.

Seiders V. M. (1971) Geologic map of the El Yunque quadrangle, Puerto Rico. U.S. Geol. Survey Misc. Geol. Inv., Map I-658.

Stille P., Steinmann M., Pierret M. C., Gauthier-Lafaye F., Chabaux F., Viville D., Pourcelot L., Matera V., Aouad G. and Aubert D. (2006) The impact of vegetation on REE fractionation in stream waters of a small forested catchment (the Strengbach case). Geochim. Cosmochim. Acta 70, 32173230 .

Stille P., Pierret M.-C., Steinmann M., Chabaux F., Boutin R., Aubert D., Pourcelot L. and Morvan G. (2009) Impact of atmospheric deposition, biogeochemical cycling and watermineral interaction on REE fractionation in acidic surface soils and soil water (the Strengbach case). Chem. Geol. 264, 173-186.

Sueoka T. (1988) Identification and classification of granite residual soils using chemical weathering index. Symposium on the Weathering Residual Soil. pp. 89-94.

Taylor S. R. and McLennan S. M. (1995) The geochemical evolution of the continental crust. Rev. Geophys. 33, 241-265.

Taylor G. and Eggleton R. A. (2001) Regolith Geology and Geomorphology. John Wiley \& Sons, Ltd., Chichester.

Turner B. F., Stallard R. F. and Brantley S. L. (2003) Investigation of in situ weathering of quartz diorite bedrock in the Rio Icacos basin, Luquillo Experimental Forest, Puerto Rico. Chem. Geol. 202, 313-341.

Viville D., Chabaux F., Stille P., Pierret M. C. and Gangloff S. (2012) Erosion and weathering fluxes in granitic basins: Example of the Strengbach catchment (Vosges Massif, Eastern France). Catena 92, 122-129.

Von Blanckenburg F. (2005) The control mechanisms of erosion and weathering at basin scale from cosmogenic nuclides in river sediment. Earth Planet. Sci. Lett. 237, 462-479.

White A. F. (2002) Determining mineral weathering rates based on solid and solute weathering gradients and velocities: Application to biotite weathering in saprolites. Chem. Geol. 190, 69-89.

White A. F., Blum A. E., Schulz M. S., Vivit D. V., Stonestrom D. A., Larsen M., Murphy S. F. and Eberl D. (1998) Chemical weathering in a tropical watershed, Luquillo Mountains, Puerto Rico: I. Long-term versus short-term weathering fluxes. Geochim. Cosmochim. Acta 62, 209-226.

Zhu C., Byrd R. H., Lu P. and Nocedal J. (1997) Algorithm 778: LBFGS-B: Fortran subroutines for large-scale bound constrained optimization. ACM Trans. Math. Softw. 23(4), 550560 .

Associate editor: S. Krishnaswami 